
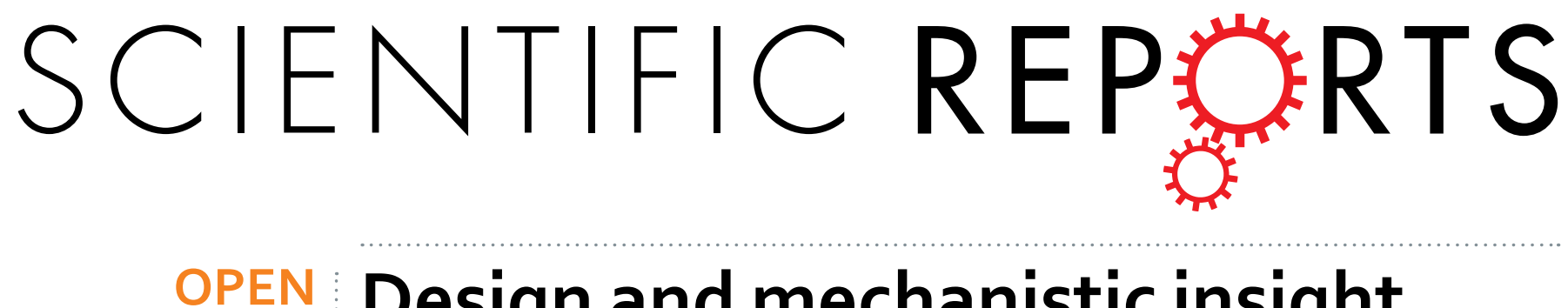

\title{
Design and mechanistic insight
} into ultrafast calcium indicators for monitoring intracellular calcium

Received: 22 April 2016 dynamics

\author{
Nordine Helassa ${ }^{1}$, Borbala Podor ${ }^{2}$, Alan Fine ${ }^{2} \&$ Katalin Török ${ }^{1}$
}

Calmodulin-based genetically encoded fluorescent calcium indicators (GCaMP-s) are powerful tools of imaging calcium dynamics from cells to freely moving animals. High affinity indicators with slow kinetics however distort the temporal profile of calcium transients. Here we report the development of reduced affinity ultrafast variants of GCaMP6s and GCaMP6f. We hypothesized that GCaMP-s have a common kinetic mechanism with a rate-limiting process in the interaction of the RS20 peptide and calcium-calmodulin. Therefore we targeted specific residues in the binding interface by rational design generating improved indicators with $\mathrm{GCaMP6f}_{u}$ displaying fluorescence rise and decay times $\left(t_{1 / 2}\right)$ of 1 and $3 \mathrm{~ms}\left(37^{\circ} \mathrm{C}\right)$ in vitro, 9 and 22 -fold faster than GCaMP6f respectively. In HEK293T cells, GCaMP6f $f_{u}$ revealed a 4-fold faster decay of ATP-evoked intracellular calcium transients than GCaMP6f. Stimulation of hippocampal CA1 pyramidal neurons with five action potentials fired at $100 \mathrm{~Hz}$ resulted in a single dendritic calcium transient with a 2 -fold faster rise and 7 -fold faster decay time ( $t_{1 / 2}$ of $40 \mathrm{~ms}$ ) than GCaMP6f, indicating that tracking high frequency action potentials may be limited by calcium dynamics. We propose that the design strategy used for generating GCaMP6f $f_{u}$ is applicable for the acceleration of the response kinetics of GCaMP-type calcium indicators.

Genetically encoded $\mathrm{Ca}^{2+}$ indicators (GECI) facilitated monitoring $\mathrm{Ca}^{2+}$ dynamics in intact and even freely moving animals. A limiting factor in the application of GECI has been their high $\mathrm{Ca}^{2+}$ affinity and slow response kinetics ${ }^{1}$. In GCaMP-type $\mathrm{GECI}^{2-11} \mathrm{Ca}^{2+}$ binding to calmodulin (CaM) induces the formation of a complex with a target peptide which in turn restores the fluorescence of circularly permutated (cp) $\mathrm{EGFP}^{12}$. The $\mathrm{Ca}^{2+}$-induced binding of $\mathrm{CaM}$ to a target peptide allows the detection of $\mathrm{Ca}^{2+}$ signals also by GCaMP-related G-GECO-s ${ }^{13}$, GEM-GECO-s $\mathrm{s}^{13}$ and sub-cellularly targeted CEPIA ${ }^{14}$ and GCaMPer ${ }^{15}$. Further broadening of the approaches for non-invasive mapping of neuronal circuits is represented by the development of red fluorescent probes for optogenetic stimulation and of photoactivatable derivatives ${ }^{13,16-18}$. The most commonly used target peptide is RS20, a smooth muscle myosin light chain kinase-derived peptide and, in the case of RCaMP2, a CaMKK $\alpha$-derived peptide ${ }^{16}$. GCaMP-s reported to have the greatest brightness and $\mathrm{Ca}^{2+}$ induced fluorescence enhancement to date are variants of a GCaMP6 generation termed GCaMP6 slow, GCaMP6 medium and GCaMP6 fast (GCaMP6s, GCaMP6m and GCaMP6f $)^{19}$ as well as GCaMP7 ${ }^{20}$ and GCaMP8 ${ }^{21}$. Even though indicators such as GCaMP7 show sufficiently high level of brightness to detect single action potentials (AP-s) ${ }^{22}$, their slow kinetic properties due to the $\mathrm{Ca}^{2+}$ - CaM - RS20 peptide interaction limit achieving temporal fidelity. Typically, $\mathrm{Ca}^{2+}$ - $\mathrm{CaM}_{\text {- }}$ RS20 interactions have a high affinity (half-maximal brightness concentration, $K_{\mathrm{d}}$ values of $100-300 \mathrm{nM}$ ) as for GCaMP6s and GCaMP6f ${ }^{19}$. Correspondingly, the $\mathrm{Ca}^{2+}$ dissociation rates and thus the signal decay rates are slow, $1-5 \mathrm{~s}^{-1}$ at $20^{\circ} \mathrm{C}$, comparable to that of $\mathrm{GCaMP}^{10}$. By rational design, mutations at the $\mathrm{Ca}^{2+}$ - CaM - RS20 binding interface have produced GCaMP3- and GCaMP6f-derived probes with improved decay kinetics ${ }^{23,24}$. The probe with the fastest signal rise $\left(t_{1 / 2}\right.$ of $\left.1 \mathrm{~ms}\right)$ and decay $\left(t_{1 / 2}\right.$ of $\left.3 \mathrm{~ms}\right)$ kinetics $\left(37^{\circ} \mathrm{C}\right)$ so far is GCaMP $3_{\text {fast }}{ }^{25}$. The mutation strategy that gave rise to GCaMP $3_{\text {fast }}$ can serve as a template for generating fast-response CaM-based GECI.

${ }^{1}$ Molecular and Clinical Sciences Research Institute, St George's, University of London, Cranmer Terrace, London SW17 ORE, UK. '2Department of Physiology and Biophysics, Dalhousie University, Halifax, Nova Scotia, Canada. Correspondence and requests for materials should be addressed to K.T. (email: k.torok@sgul.ac.uk) 

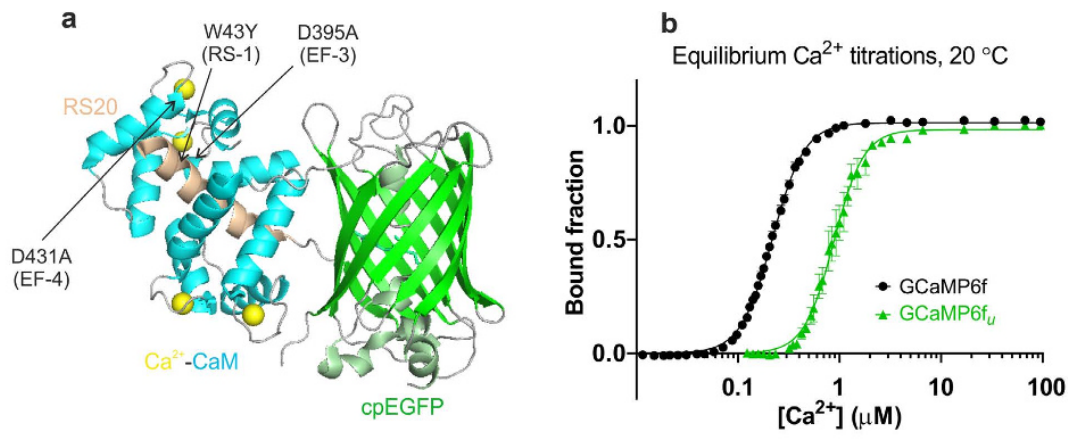

C
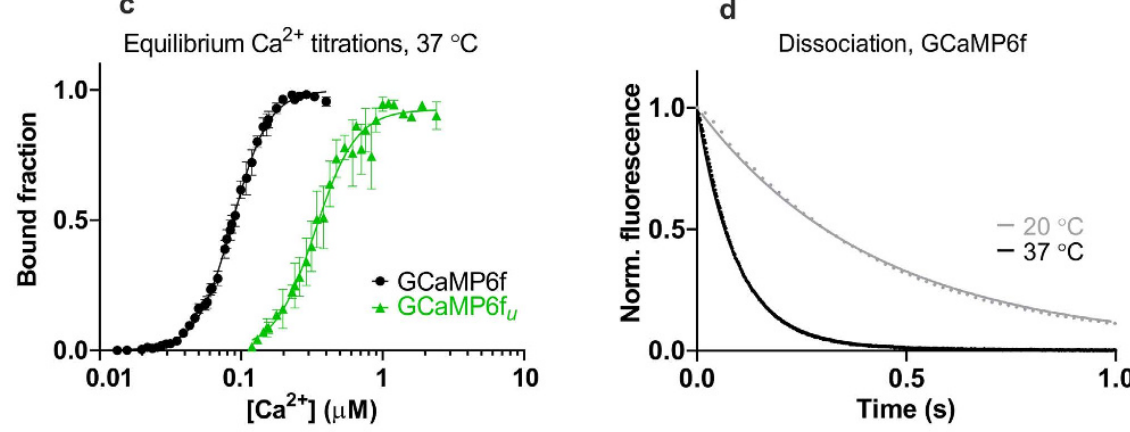

e Dissociation, GCaMP6f ${ }_{u}$

f
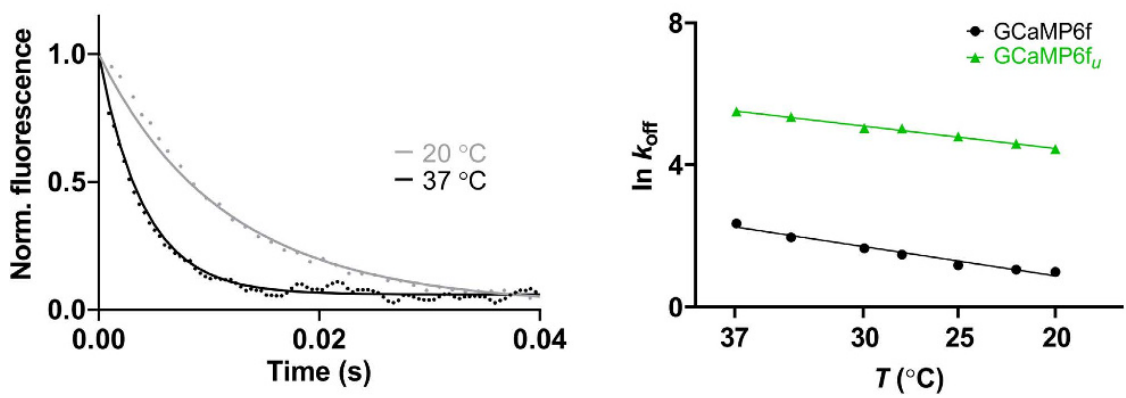

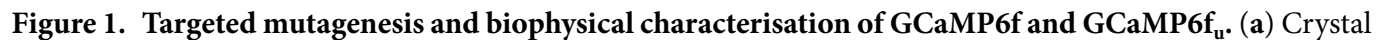
structure of monomeric GCaMP6m in a $\mathrm{Ca}^{2+}$-bound form with cpEGFP (green), $\mathrm{Ca}^{2+}$ ions (yellow), CaM (blue) and the RS20 peptide (light brown) (adapted from Ding et al., ${ }^{27}$ PDB 3WLD). The positions of the mutated amino acid residues in the CaM EF-hand $\mathrm{Ca}^{2+}$-binding sites and in the RS20 peptide are highlighted. Equilibrium $\mathrm{Ca}^{2+}$ titrations for GCaMP6f $(\bullet)$ and $\mathrm{GCaMP}_{u}(\triangle),(\mathbf{b})$ at $20^{\circ} \mathrm{C}(\mathbf{c})$ at $37^{\circ} \mathrm{C}$. Fluorescence changes are normalised to $F_{0}$ of 0 and $F_{\max }$ of 1 and fitted to the Hill equation. Fitted curves are represented by solid lines overlaying the data points. $\mathrm{Ca}^{2+}$ dissociation kinetics of (d) GCaMP6f and (e) $\mathrm{GCaMP} 6 \mathrm{f}_{u}$ at $20^{\circ} \mathrm{C}$ $(-)$ and $37^{\circ} \mathrm{C}(-)$; Experimental data are overlaid by fitted curves using parameters for the kinetic model for GCaMPs (Supplementary Table S3). (f) Arrhenius plots of the observed rates for $\mathrm{Ca}^{2+}$ dissociation of GCaMP6f $(\bullet)$ and $\mathrm{GCaMP}_{u}(\Delta)$.

\section{Design template for ultrafast GCaMP-s}

We developed a strategy to generate fast-response GCaMP-type GECI by introducing specific mutations at the $\mathrm{Ca}^{2+}$ - CaM - RS20 peptide interface to weaken their interactions. In CaM, $\mathrm{Ca}^{2+}$ binding sites are disabled by asingle-point mutation of the first Asp to Ala in each EF-hand $\mathrm{Ca}^{2+}$ binding loop. The EF-3 mutation denotes a mutant with the third $\mathrm{Ca}^{2+}$ site inactivated, EF-4 with the fourth site. A mutation termed RS- 1 which substitutes the Trp residue in position 43 for Tyr in the RS20 peptide sequence, further weakens the $\mathrm{Ca}^{2+}$ - $\mathrm{CaM}$ - peptide interaction $^{26}$ (Fig. 1a). Four trends are commonly observed when the mutational strategy is applied to GCaMP3, G-GECO and GEM-GECO. First, mutation of EF-1 and/or EF-2 causes loss of fluorescence signal ${ }^{24,25}$. Second, the EF-4 and combined RS-1 EF-4 mutations consistently retain or have increased brightness and dynamic range together with faster kinetics than the parent proteins ${ }^{25}$. Third, GCaMP3, G-GECO and GEM-GECO probes with the EF-3:4 double mutation alone or in combination with RS-1 have low affinity ( $\mathrm{mM} K_{\mathrm{d}}$ ) and fast kinetics. Although the lower brightness and dynamic range of the EF-3:4 double mutants requires improvement, kinetically they are thus promising for development of extracellular or intra-organelle $\mathrm{Ca}^{2+}$ probes. Finally, the combination of mutations EF-3 and RS-1 results in the fastest response kinetics and has given the to-date most kinetically improved probe mGCaMP3 RS-1 EF-3 $\left(\mathrm{GCaMP}_{\text {fast }}\right)$ which has $\mathrm{Ca}^{2+}$ rise and decay times of $1-3 \mathrm{~ms}^{25}$. 


\begin{tabular}{|c|c|c|c|c|c|c|c|c|c|c|}
\hline & & \multicolumn{2}{|c|}{$F_{\mathrm{r}}$} & \multirow[b]{2}{*}{$F_{\mathrm{r}}\left(+\mathrm{Ca}^{2+}\right) / F_{\mathrm{r}}\left(-\mathrm{Ca}^{2+}\right)$} & \multirow[b]{2}{*}{$K_{\mathrm{d}}(\mu \mathrm{M})$} & \multirow[b]{2}{*}{$n$} & \multirow[b]{2}{*}{$k_{\text {on }}\left(\mathrm{s}^{-1}\right)$} & \multirow[b]{2}{*}{$t_{1 / 2(\mathrm{on})}(\mathrm{ms})$} & \multirow[b]{2}{*}{$k_{\text {off }}\left(\mathrm{s}^{-1}\right)$} & \multirow[b]{2}{*}{$t_{1 / 2 \text { (off) }}(\mathrm{ms})$} \\
\hline & & $-\mathrm{Ca}^{2+}$ & $+\mathrm{Ca}^{2+}$ & & & & & & & \\
\hline \multirow{3}{*}{ GCaMP6f } & \multirow{2}{*}{$20^{\circ} \mathrm{C}$} & \multirow{2}{*}{$0.9 \pm 0.1$} & \multirow{2}{*}{$14.4 \pm 3.4$} & \multirow{2}{*}{$14.6 \pm 2.4$} & \multirow{2}{*}{$0.22 \pm 0.01$} & \multirow{2}{*}{$2.8 \pm 0.1$} & $315 \pm 9(0.3)^{\mathrm{a}}$ & $2.2 \pm 0.1(0.3)^{\mathrm{a}}$ & \multirow{2}{*}{$2.4 \pm 0.1$} & \multirow{2}{*}{$288 \pm 12$} \\
\hline & & & & & & & $38 \pm 1(0.7)^{\mathrm{a}}$ & $18 \pm 0.5(0.7)^{\mathrm{a}}$ & & \\
\hline & $37^{\circ} \mathrm{C}$ & $1.0 \pm 0.1$ & $13.8 \pm 0.1$ & $13.2 \pm 0.1$ & $0.09 \pm 0.01$ & $3.4 \pm 0.1$ & $66 \pm 1$ & $10 \pm 0.2$ & $11 \pm 1$ & $63 \pm 6$ \\
\hline \multirow{2}{*}{$\begin{array}{l}\text { GCaMP6f }_{u} \\
\text { (mGCaMP6f RS-1 EF-3) }\end{array}$} & $20^{\circ} \mathrm{C}$ & $1.0 \pm 0.1$ & $5.1 \pm 0.4$ & $5.1 \pm 0.1$ & $0.89 \pm 0.01$ & $3.0 \pm 0.1$ & $142 \pm 4$ & $4.9 \pm 0.1$ & $89 \pm 1$ & $7.8 \pm 0.1$ \\
\hline & $37^{\circ} \mathrm{C}$ & $0.9 \pm 0.1$ & $3.8 \pm 0.2$ & $4.1 \pm 0.2$ & $0.34 \pm 0.01$ & $3.0 \pm 0.3$ & $546 \pm 44^{\mathrm{b}}$ & $1.3 \pm 0.02^{\mathrm{b}}$ & $245 \pm 10$ & $2.8 \pm 0.1$ \\
\hline
\end{tabular}

Table 1. Comparison of the biophysical characteristics of GCaMP6f and GCaMP6f ${ }_{u} \cdot{ }^{\text {aBiphasic association }}$ kinetic records were fitted with two exponentials. The rise $t_{1 / 2}$ of each phase is given with the relative amplitudes in parentheses. ${ }^{\mathrm{b}}$ Measurements were made in the range of 15 to $30^{\circ} \mathrm{C}$. The rate was too fast to measure at $37^{\circ} \mathrm{C}$ and was extrapolated from the Arrhenius plot assuming the gradient remaining unchanged (Fig. 2e).

We applied the strategy used to produce GCaMP3 $3_{\text {fast }}$ to the popular bright probes GCaMP6s and GCaMP6f. Here we test the hypothesis that the EF-3, EF-4 and RS-1 mutations and their combinations result in significantly faster kinetics when applied to CaM-based GECI. We have generated twelve mutant probes, six each for GCaMP6s and for GCaMP6 $\mathrm{f}^{19}$. Biophysical characterisation revealed that, as predicted, the fastest responding probe was given by the RS-1 (W43Y) EF-3 (D395A) mutation combination. mGCaMP6f RS-1 EF-3, termed GCaMP6f-ultrafast $\left(\mathrm{GCaMP}_{u}\right)$ has $1 \mathrm{~ms}$ rise and $3 \mathrm{~ms}$ decay half times in vitro $\left(37^{\circ} \mathrm{C}\right)$. The temperature dependence of the fluorescence response kinetics of the probes is analyzed to enable predictions for physiological applications and for better understanding of the molecular mechanisms of GCaMP probes. A kinetic model is proposed for the processes through which fluorescence develops in CaM-based GCaMP-s. Faster response kinetics by GCaMP6f $_{u}$ compared to GCaMP6f are demonstrated in ATP-stimulated cells and in neurons stimulated by high frequency action potentials.

\section{Results}

Biophysical properties of GCaMP6f ${ }_{u}$ and selected mGCaMP6s and mGCaMP6f. First the effects of the mutations on the fluorescence brightness and dynamic range of the probes were determined. Quantum yield $\left(\Phi_{+\mathrm{Ca}}{ }^{2+}\right)$ measurements revealed that the EF-4 and RS-1 EF-4 mutations had little effect on the $\Phi_{+\mathrm{Ca}}{ }^{2+}$ of GCaMP6s and GCaMP6f. Using the reported value of 0.59 at $20^{\circ} \mathrm{C}$ for GCaMP $6 \mathrm{f}^{19}$, we obtained a $\Phi_{+\mathrm{Ca}}{ }^{2+}$ value of 0.58 for GCaMP6s and 0.46 for GCaMP $6 \mathrm{f}_{u}$. With measured molar extinction coefficients $\varepsilon_{\mathrm{o}(497 \mathrm{~nm})}$ of $50294 \pm 259 \mathrm{M}^{-1} \mathrm{~cm}^{-1}$ for $\mathrm{Ca}^{2+}$-saturated GCaMP6f and $1564 \pm 1140 \mathrm{M}^{-1} \mathrm{~cm}^{-1}$ for $\mathrm{Ca}^{2+}$-saturated GCaMP6f $\mathrm{f}_{u}$, brightness values of 29673 and $7197 \mathrm{M}^{-1} \mathrm{~cm}^{-1}$ were obtained for GCaMP6f and GCaMP6f $\mathrm{f}_{u}$, respectively. Similarly, $\mathrm{Ca}^{2+}$-induced fluorescence increases $\left(F_{\mathrm{r}}\left(+\mathrm{Ca}^{2+}\right)\right)$, expressed relative to apo-GCaMP6s $\left(F_{\mathrm{r}}\left(-{ }_{-}{ }^{2+}\right)\right.$ of 1)) of 27 for GCaMP6s and 15 for GCaMP $6 \mathrm{f}^{19}$, were little affected by the EF- 4 and RS-1 EF- 4 mutations. $F_{\mathrm{r}}\left(+\mathrm{Ca}{ }^{2+}\right) / F_{\mathrm{r}}\left(\mathrm{Cla}^{2+}\right)$ of GCaMP6s RS-1 EF-3 and GCaMP6f $\mathrm{f}_{u}$ were reduced to 18 and 5, respectively (Table 1 and Supplementary Table S1). Even though the brightness for GCaMP6f $f_{u}$ is 4 -fold reduced compared to GCaMP6f, the value remains comparable to GCaMP3 probe which has been widely used for in vivo experiments including calcium measurements in free-moving animals $\left(F_{\max } / F_{\min }\right.$ for GCaMP6f $=14.6, \mathrm{GCaMP}_{u}=5.1$ and GCaMP3 $=6.3)^{25}$. pKa values of $\sim 7$ were measured for GCaMP6s and GCaMP6f together with their mutants at $20^{\circ} \mathrm{C}$ in agreement with previously reported values (Supplementary Fig. S1) ${ }^{19}$.

Equilibrium $\mathrm{Ca}^{2+}$ binding. The mutations were expected and found to increase the equilibrium half-maximal brightness concentration $\left(K_{\mathrm{d}}\right)$ values of the probes. Cooperativity for $\mathrm{Ca}^{2+}$ remained high, characterised by Hill coefficient $(n)$ values of $\sim 2-3$. Comparison of affinities at $20^{\circ} \mathrm{C}$ and $37^{\circ} \mathrm{C}$ revealed that $K_{\mathrm{d}}-\mathrm{s}$ decreased with increasing temperature: for GCaMP6f, from $220 \mathrm{nM}$ to $88 \mathrm{nM}$, respectively (Fig. 1b), for GCaMP6f from $890 \mathrm{nM}$ to $340 \mathrm{nM}$ (Fig. 1c, Table 1) and for the lower affinity mGCaMP6f EF-4, from 1.6 $\mu \mathrm{M}$ to $840 \mathrm{nM}$ (Supplementary Fig. S2,S3, Supplementary Table S1).

mGCaMP6f RS-1 EF-4 and the EF-3:4 double mutants of both GCaMP6s and GCaMP6f revealed two independent sets of $\mathrm{Ca}^{2+}$ binding sites: high affinity $\left(1-6 \mu \mathrm{M} K_{\mathrm{d}}\right)$ with $n$ of 2 and low affinity $\left(0.2-6 \mathrm{mM} K_{\mathrm{d}}\right)$ with $n$ of 1 . The high affinity $K_{\mathrm{d}}$ decreased with temperature while the low affinity $K_{\mathrm{d}}$ increased. Moreover, while $80 \%$ of the total fluorescence enhancement of mGCaMP6f RS-1 EF- 4 occurred with high affinity at $20^{\circ} \mathrm{C}$, at $37^{\circ} \mathrm{C}$, a temperature closer to those in physiological applications, the lower affinity component dominated representing $70 \%$ of the signal (Supplementary Fig. S3 and Supplementary Table S1, S2). The apparent binding to three sites shown by the EF-3:4 double mutants may be explained by residual $\mathrm{Ca}^{2+}$ binding to a mutated C-lobe site.

$\mathrm{Ca}^{2+}$ decay kinetics. Typically, faster fluorescence decay rates were expected for the EF-3, EF-4 and RS-1 mutants of GCaMP6s and GCaMP6f compared to their parent proteins at all temperatures (Supplementary Fig. S4, S5). $t_{1 / 2}$ at $20^{\circ} \mathrm{C}$ of $769 \mathrm{~ms}$ for GCaMP6s was reduced to $216 \mathrm{~ms}$ by the RS- 1 EF- 3 mutation. The same mutation in GCaMP6f, giving GCaMP6f $f_{u}$ brought down the decay $t_{1 / 2}$ from $288 \mathrm{~ms}$ to $7.8 \mathrm{~ms}$ (Fig. 1e, Table 1 and Supplementary Table S1).

In spite of decreasing $K_{\mathrm{d}}$ values by increased temperatures, the fluorescence decay rates were 2-5-fold increased at $37^{\circ} \mathrm{C}$ compared to $20^{\circ} \mathrm{C}$ (Supplementary Fig. S4,S5 and Supplementary Tables S1,S2). At $37^{\circ} \mathrm{C}$, the fastest mGCaMP6s probe, mGCaMP6s RS-1 EF-3, had a 6.5-fold increased $\mathrm{Ca}^{2+}$ decay rate compared to GCaMP6s with the $t_{1 / 2}$ of $346 \mathrm{~ms}$ reduced to $53 \mathrm{~ms}$. $t_{1 / 2}$ at $20^{\circ} \mathrm{C}$ of $288 \mathrm{~ms}$ of GCaMP6f was reduced to $63 \mathrm{~ms}$ at $37^{\circ} \mathrm{C}$ (Fig. 1d). The most significant improvements in the $\mathrm{Ca}^{2+}$ dissociation kinetics were however achieved by 
the RS-1 EF-3 mutations of GCaMP6f yielding the probe GCaMP6f $\mathrm{f}_{u}$ with a 23 -fold faster fluorescence decay $t_{1 / 2}$ of $3 \mathrm{~ms}$ at $37^{\circ} \mathrm{C}$ (Fig. If and Supplementary Fig. S6).

$\mathrm{Ca}^{2+}$ rise kinetics. Stopped-flow fluorimetry revealed biphasic $\mathrm{Ca}^{2+}$ association kinetics for both GCaMP6s and GCaMP6f and for most of their mutants at $20^{\circ} \mathrm{C}$. The exceptions were mGCaMP6s RS-1 EF-4, GCaMP6f $f_{u}$ and mGCaMP6f EF-3:4 which had a monophasic fluorescence rise (Fig. 2 and Supplementary Fig. S7, S8). [Ca ${ }^{2+}$ ] dependency of the rise rates revealed a switch-like response with limiting rates for each phase $\left(k_{\text {on }(\lim )}\right)$. The fastest rate was measured for GCaMP6f $f_{u}$ which, responding in an all-or-none manner to $\left[\mathrm{Ca}^{2+}\right]$ rise, had a single rise $t_{1 / 2}$ of $5 \mathrm{~ms}$ at $20^{\circ} \mathrm{C}$ (Fig. $2 \mathrm{c}$ ).

Examination of the temperature dependence of the $\mathrm{Ca}^{2+}$ rise kinetics reveals the kinetic advantage of GCaMP6f $f_{u}$ over GCaMP6f at $37^{\circ} \mathrm{C}$ (Fig. 2 and Supplementary Fig. S9). The fast phase of $\mathrm{Ca}^{2+}$ induced fluorescence enhancement of GCaMP6f has a limiting rate of $315 \mathrm{~s}^{-1}$ (rise $t_{1 / 2} 2 \mathrm{~ms}$ ) and at $20^{\circ} \mathrm{C}$ represents $30 \%$ of the fluorescence enhancement. The rate of the fast phase is essentially independent of temperature in the range of $20^{\circ} \mathrm{C}$ to $30^{\circ} \mathrm{C}$, however with a diminishing amplitude of only $10 \%$ at $30^{\circ} \mathrm{C}$ and no longer measurable at $37^{\circ} \mathrm{C}$. The rate of the slow phase is $\sim 2$-fold increased from $38 \mathrm{~s}^{-1}$ to $66 \mathrm{~s}^{-1}$ over the temperature range of $20^{\circ} \mathrm{C}$ to $37^{\circ} \mathrm{C}$, representing the only measurable rate for GCaMP $6 \mathrm{f}$ at $37^{\circ} \mathrm{C}$. The apparent $\mathrm{Ca}^{2+}$ response of GCaMP6f is thus slower at $37^{\circ} \mathrm{C}$ than $20^{\circ} \mathrm{C}$. In contrast, the single observed limiting rate for mGCaMP6f RS-1 EF-3 (GCaMP6f $f_{u}$ ) is $\sim 4$-fold increased, to an extrapolated $546 \mathrm{~s}^{-1}$ at $37^{\circ} \mathrm{C}$, from $142 \mathrm{~s}^{-1}$ at $20^{\circ} \mathrm{C}$ giving a fluorescence rise time of $1 \mathrm{~ms}$.

Complexities are revealed in the temperature dependencies of the $\mathrm{Ca}^{2+}$ rise kinetics of GCaMP6s and mGCaMP-s as well (Fig. 2, Supplementary Fig. S10). In the case of GCaMP6s, the relative amplitudes of the fast and slow phases change with temperature such that at physiological ionic strength and $20^{\circ} \mathrm{C}$ the amplitudes are about even, however at $37^{\circ} \mathrm{C}$ the slow phase (rise $t_{1 / 2} 12 \mathrm{~ms}$ ) represents $90 \%$ of the signal (Supplementary Table S1). Arrhenius plots for mGCaMP6f RS-1 EF-4 reveal opposite temperature dependencies for the rate of the fast and slow phases of its biphasic $\mathrm{Ca}^{2+}$ association kinetics: while the rate of the fast phase is 2 -fold increased, the rate of the slow decay component is 2.5 -fold lowered when the temperature increases from $20^{\circ} \mathrm{C}$ to $37^{\circ} \mathrm{C}$ (Supplementary Fig. S11d and Supplementary Table S1).

Kinetic mechanism of GCaMP-type GECI. As the fluorescence increase evoked by $\mathrm{Ca}^{2+}$ is based on the effect of the $\mathrm{Ca}^{2+}$ - CaM - RS20 peptide interaction on the structure of the cpEGFP domain, a common reaction mechanism previously described for GCaMP3 and its fast variants is expected to operate for GCaMP-s in general ${ }^{25}$. In essence, partially and fully $\mathrm{Ca}^{2+}$ - and peptide-bound intermediates create two main fluorescent states in the rise phase of $\mathrm{Ca}^{2+}$-induced fluorescence. In the decay phase evoked by $\mathrm{Ca}^{2+}$ sequestration, $\mathrm{Ca}^{2+}$ leaving initiates dissociation of the complex and the return to the resting low-fluorescence state (Fig. 3). Fitted curves to the stopped-flow kinetic $\mathrm{Ca}^{2+}$ association and dissociation records obtained at $20^{\circ} \mathrm{C}, 30^{\circ} \mathrm{C}$ and $37^{\circ} \mathrm{C}$ for GCaMP6f and GCaMP6f ${ }_{u}$ were generated using a set of fitted parameters consistent with the data (Fig. 2 and Supplementary Table S3).

Fluorescence dynamic range measurements of GCaMP6f and GCaMP6s variants in HEK293T cells. Fluorescence dynamic range values for mGCaMP6s and mGCaMP6f probes were measured in ionomycin stimulated HEK293T cells. GCaMP6s continued to have the greatest fluorescence enhancement with $\Delta F / F_{0}$ of 18 . In contrast to $\Delta F / F_{0}$ for GCaMP6f of $11, \mathrm{GCaMP}_{\mathrm{f}}$ had $\Delta F / F_{0}$ of $\sim 7$. Fluorescence dynamic range values obtained in cellular environment were generally reduced compared to those in solution, except for GCaMP6f $\mathrm{f}_{u}$, and for mGCaMP6s EF-3:4 (Supplementary Fig. S12).

Imaging intracellular $\mathrm{Ca}^{2+}$ release dynamics in ATP-stimulated HEK293T cells by GCaMP6f, GCaMP6f $f_{v}$ and mGCaMP6f RS-1 EF-4. Intracellular $\mathrm{Ca}^{2+}$ dynamics were monitored in ATP-stimulated HEK293T cells and the time courses of the $\mathrm{Ca}^{2+}$ transient evoked by GCaMP6f, GCaMP6f $f_{u}$ and mGCaMP6f RS-1 EF-4 were compared. GCaMP6f fluorescence increased $\left(\Delta F / F_{0}\right.$ of $\left.3.1 \pm 0.35\right)$ with a decay time $t_{1 / 2}$ of $9.4 \pm 0.2 \mathrm{~s}$. In comparison, GCaMP6f $f_{u}$ and mGCaMP6f RS- 1 EF- 4 both showed lower dynamic ranges $\left(\Delta F / F_{0}\right.$ of $\left.0.2 \pm 0.02\right)$ and significantly reduced, $2.3 \pm 0.04 \mathrm{~s}$ decay time. Faster probes GCaMP $6 \mathrm{f}_{u}$ and mGCaMP6f RS-1 EF-4 thus revealed that ATP-induced intracellular $\mathrm{Ca}^{2+}$ release dynamics were more rapid than reported by GCaMP6f (Fig. 4a).

Response of GCaMP6f, GCaMP6f $f_{u}$ and mGCaMP6f RS-1 EF-4 to high frequency stimulation in neurons. GCaMP6f, GCaMP6f ${ }_{u}$ and mGCaMP6f RS-1 EF-4 expressed in hippocampal CA1 pyramidal neurons in organotypic hippocampal slices were distributed homogenously. Baseline fluorescence of all three indicators was bright enough to readily identify expressing cells. Fluorescence dynamic ranges $\left(\Delta F / F_{0}\right)$ were $5.9 \pm 0.3$, $0.8 \pm 0.05$ and $0.5 \pm 0.04$ for GCaMP6f, GCaMP6f $f_{u}$ and mGCaMP6f RS- 1 EF-4, respectively, consistent with small $\left[\mathrm{Ca}^{2+}\right]$ changes. Notably, GCaMP6f achieved a significantly higher $\Delta F / F_{0}$ value throughout the $10-100 \mathrm{~Hz}$ range tested compared to GCaMP6f ${ }_{u}$ and mGCaMP6f RS-1 EF-4. Due to its low $K_{\mathrm{d}}$ for $\mathrm{Ca}^{2+}$, only GCaMP6f was able to detect the low post-synaptic $\left[\mathrm{Ca}^{2+}\right]$ elevation evoked by $5 \mathrm{AP}$-s fired at $10 \mathrm{~Hz}$. For the same reason, however, the

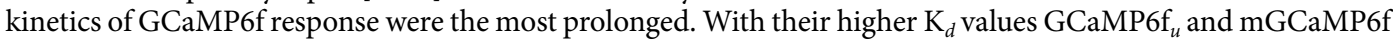
RS-1 EF-4 did not show a response to stimulation up to $20-40 \mathrm{~Hz}$ frequency and the dynamic range remained low. The kinetic advantage of GCaMP6f $\mathrm{f}_{u}$ and mGCaMP6f RS-1 EF-4 became evident at stimulation at $40 \mathrm{~Hz}$ or greater (Fig. 4b,c and Supplementary Fig. S13) and was particularly clear at $100 \mathrm{~Hz}$ : compared to GCaMP6f, GCaMP6f and mGCaMP6f RS-1 EF-4 responded with much faster rise and decay kinetics to the $\left[\mathrm{Ca}^{2+}\right]$ elevation evoked by trains of 5 AP-s. For GCaMP6f, following $50 \mathrm{~ms}$ stimulation at $100 \mathrm{~Hz}$, the $\mathrm{Ca}^{2+}$ signal is still rising for another $\sim 75 \mathrm{~ms}$ and then decays over $\sim 400 \mathrm{~ms}^{19}$ (Fig. $4 \mathrm{~b}$ ). mGCaMP6f RS-1 EF-4 has improved kinetics with the signal decaying only $20 \mathrm{~ms}$ after stimulation, with a $t_{1 / 2}$ of $91 \pm 17 \mathrm{~ms}$ (Supplementary Fig. S13). The fastest response 

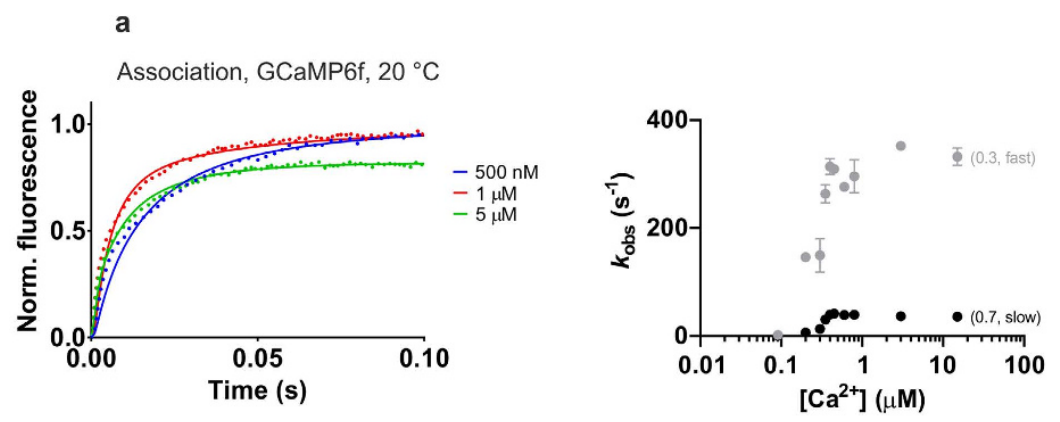

b
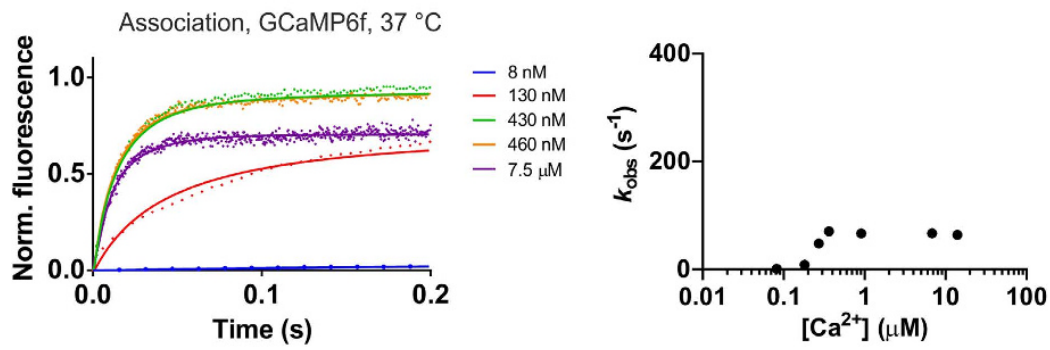

c

Association, GCaMP6f ${ }_{u}, 20^{\circ} \mathrm{C}$
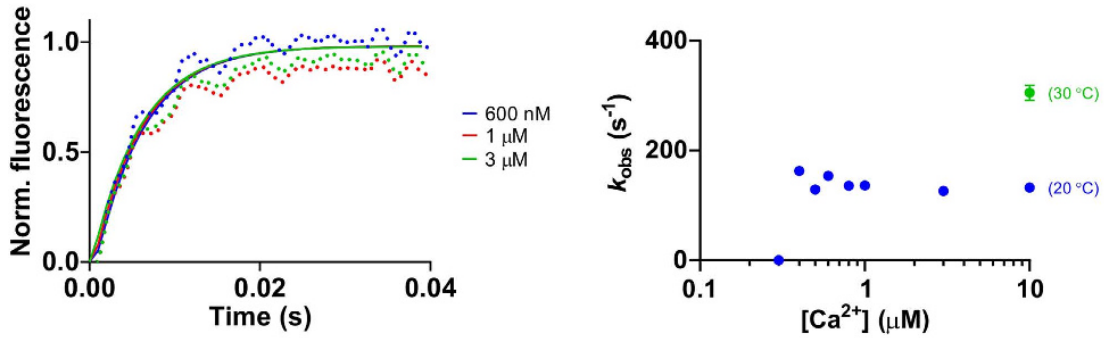

d

e
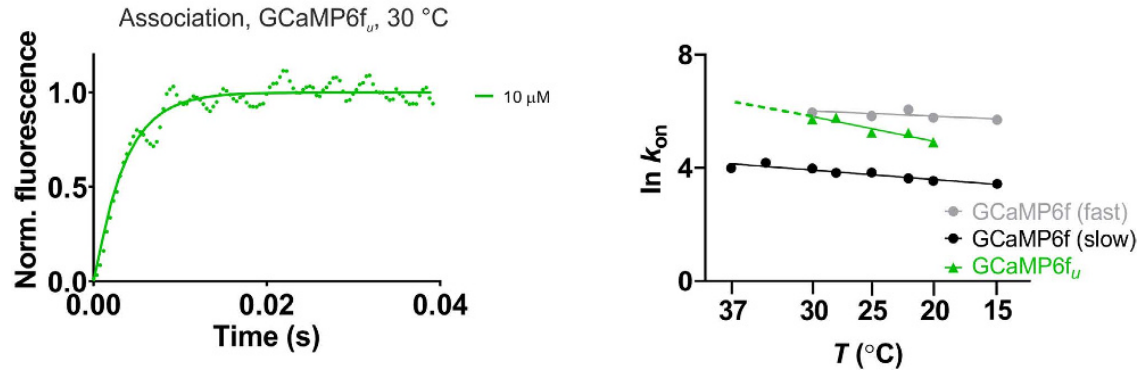

Figure 2. $\mathrm{Ca}^{2+}$ association kinetics of GCaMP6f at (a) $20^{\circ} \mathrm{C}$ and (b) $37^{\circ} \mathrm{C}$; (c) GCaMP $6 f_{u}$ at $20^{\circ} \mathrm{C}$. Left hand panels show stopped-flow records at the specified final $\left[\mathrm{Ca}^{2+}\right]$ values. Fluorescence changes are normalised to $F_{0}$ of 0 and maximum of 1 . Experimental data (dotted lines) are overlayed with fitted curves (solid lines) generated using the parameters shown in Supplementary Table S3 fitted to the kinetic model for GCaMP-s. Right hand panels show plots of the $\left[\mathrm{Ca}^{2+}\right]$ dependence of the observed rate $(\mathrm{s})\left(k_{\mathrm{obs}}\right)$. GCaMP6f has biphasic association kinetics at $20^{\circ} \mathrm{C}$; the fast phase $\left({ }^{\circ}\right)$ corresponds to $30 \%$ and the slow phase $(\bullet)$ to $70 \%$ of the fluorescence amplitude. At $37^{\circ} \mathrm{C}$, GCaMP $6 \mathrm{f} \mathrm{Ca}^{2+}$ association kinetics are monophasic with the fluorescence response shown only by the slow phase. (d) Stopped-flow record of $\mathrm{GCaMP}_{4} \mathrm{Ca}^{2+}$ association at $10 \mu \mathrm{M}$ final $\left[\mathrm{Ca}^{2+}\right]$ measured at $30^{\circ} \mathrm{C}$, fitted to the model. (e) Arrhenius plots of the observed rates for $\mathrm{Ca}^{2+}$ association of GCaMP6f fast phase $\left({ }^{\bullet}\right.$ ), slow phase $(\bullet)$, GCaMP6f $f_{u}(\triangle)$. For GCaMP6f the amplitude of the fast phase diminishes with increasing temperature: relative amplitudes are at $20^{\circ} \mathrm{C}$, fast $(0.3)$ slow $(0.7)$; at $25^{\circ} \mathrm{C}$, fast $(0.2)$ slow $(0.8)$; at $30^{\circ} \mathrm{C}$, fast (0.1) slow (0.9) and at $37^{\circ} \mathrm{C}$, fast (0) slow (1.0).

is achieved by GCaMP6f ${ }_{u}$ : the $\mathrm{Ca}^{2+}$ signal decay commences as soon as the stimulation is finished, and returns to baseline with a $t_{1 / 2}$ of $40 \pm 2 \mathrm{~ms}$, thus reducing the refractory period of detection following a stimulation event from hundreds to tens of milliseconds (Fig. 4c). 

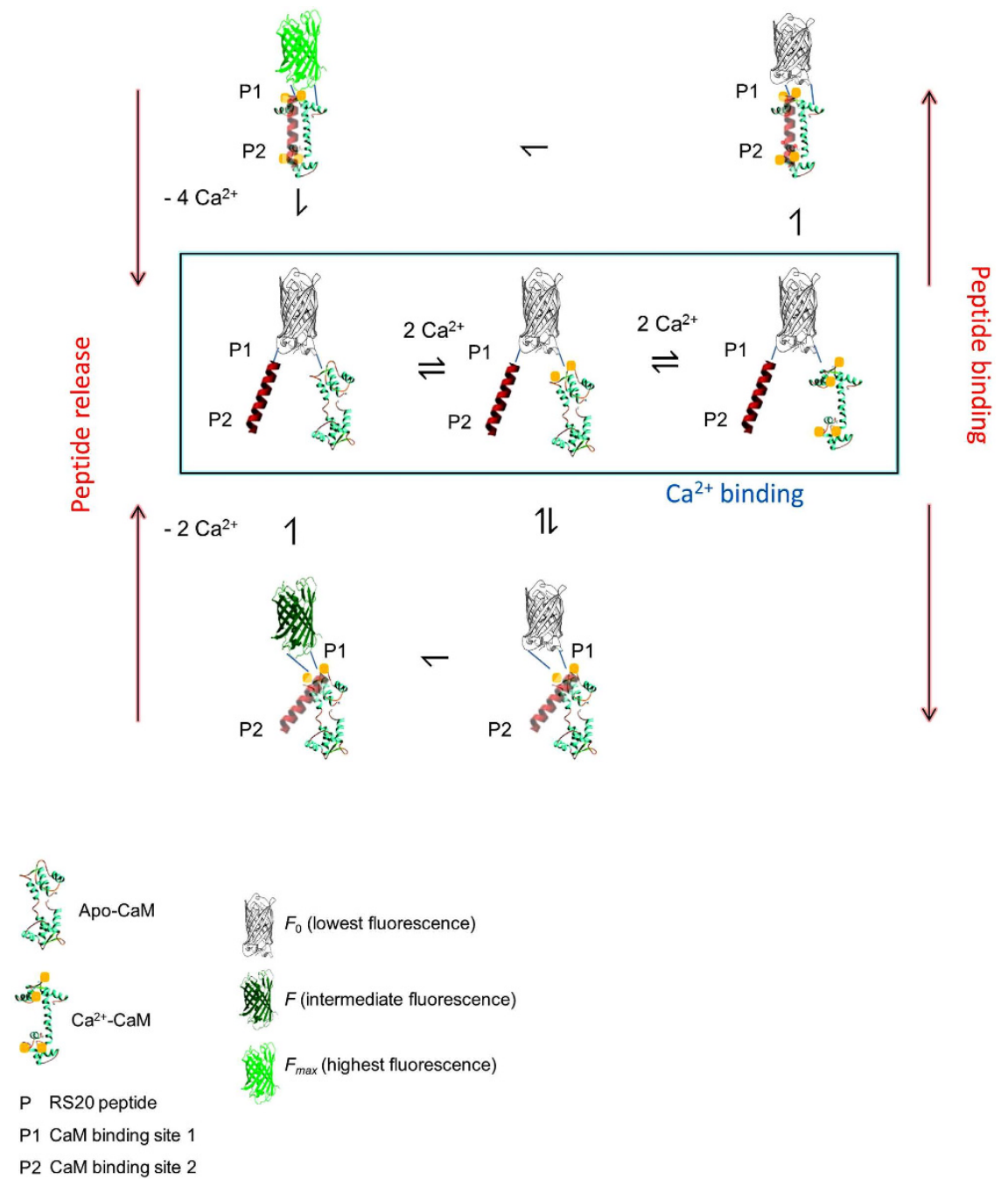

Figure 3. Schematic model of the kinetic mechanism of GCaMPs. General model for the mechanism of $\mathrm{Ca}^{2+}$-induced fluorescence of GCaMP-type probes depicting $\mathrm{Ca}^{2+}$ binding to the CaM N- and C-lobe followed by peptide binding and isomerisation leading to fluorescent states. Fluorescence is proposed to derive from the equilibrium of two states: in the first, $\mathrm{Ca}^{2+}$-bound CaM N-lobe is with the P1 CaM binding site of RS20; in the second, both the $\mathrm{N}$ - and C-lobes of CaM are $\mathrm{Ca}^{2+}$-bound binding to both the P1 and P2 sites of the peptide. Formation of the fluorescent complexes involves essentially irreversible processes. Peptide release is triggered by $\mathrm{Ca}^{2+}$ sequestration returning the complex to the apo-state. This general model for GCaMPs is applicable to EF-hand mutants by omitting the appropriate $\mathrm{Ca}^{2+}$ binding steps e.g. eq. 1 for the EF-1 mutant, eq. 2 for EF-2 and so on ${ }^{25}$.

\section{Discussion}

The aim of this work was to reveal generally applicable modifications for the generation of fast-response GCaMP-like GECI for more accurate time resolution of $\mathrm{Ca}^{2+}$ signalling events. The combination of RS-1 and EF-3 mutations gave mGCaMP3 RS-1 EF-3 (GCaMP $\left.3_{\text {fast }}\right)$ which has a $1 \mathrm{~ms}$ rise and $3 \mathrm{~ms}$ decay $t_{1 / 2}$ at $37^{\circ} \mathrm{C}^{25}$. The application of GCaMP3 $3_{\text {fast }}$ in cardiac myocytes revealed faster $\mathrm{Ca}^{2+}$ transients then previously indicated by slow indicators ${ }^{25}$. Here we report that the same design template when used on GCaMP6f results in similarly fast on and off response kinetics and propose that the RS-1 EF-3 mutation combination is applicable for the generation of ultrafast GCaMP-s.

While the RS-1 (W43Y) EF-3 (D395A) mutation pair has equal effects on the kinetics of GCaMP3 and GCaMP6f, they differently affect the brightness and dynamic range of their parent variants: GCaMP ${ }_{\text {fast }}$ retains the brightness of GCaMP3, whereas GCaMP $6 \mathrm{f}_{u}$ is 4 -fold decreased compared to GCaMP6f. Even though GCaMP6m is significantly brighter than GCaMP3, the alignment of their crystal structures (PDB codes 3SG3 and $3 \mathrm{WLD}$ ) reveals only subtle differences in the position of helix I and the linker region to cpEGFP ${ }^{3,27}$. The brightness and fluorescence dynamic range of GCaMP6f are higher than of GCaMP3 because of the introduction of the 'stabilising' mutations in the linker region connecting the CaM N-terminus to cpEGFP (T302L, R303P) and in helices I, IV and V of CaM (A317E, D380Y/T381R/S383T, R392G, respectively) (Fig. 5a,b). In particular, the T302L, R303P, D380Y hydrophobic mutations at the interface between CaM and cpEGFP result in similarly 
a
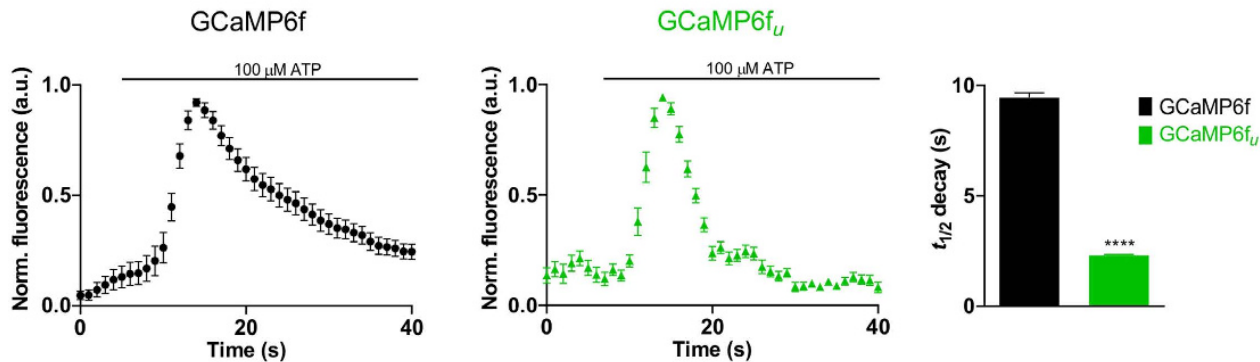

b
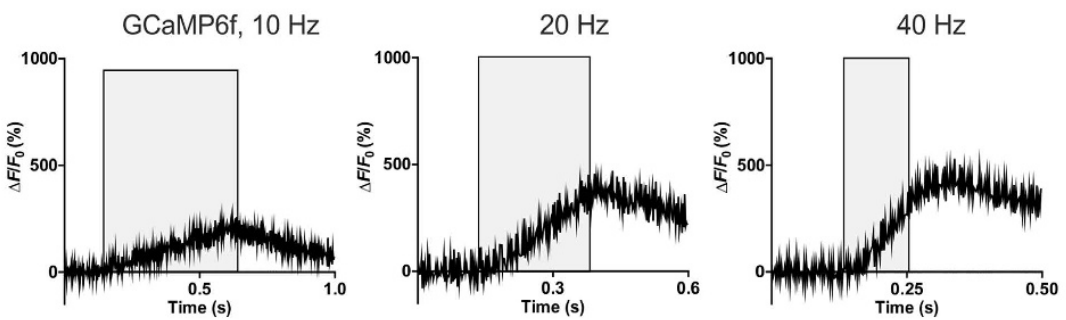

$50 \mathrm{~Hz}$
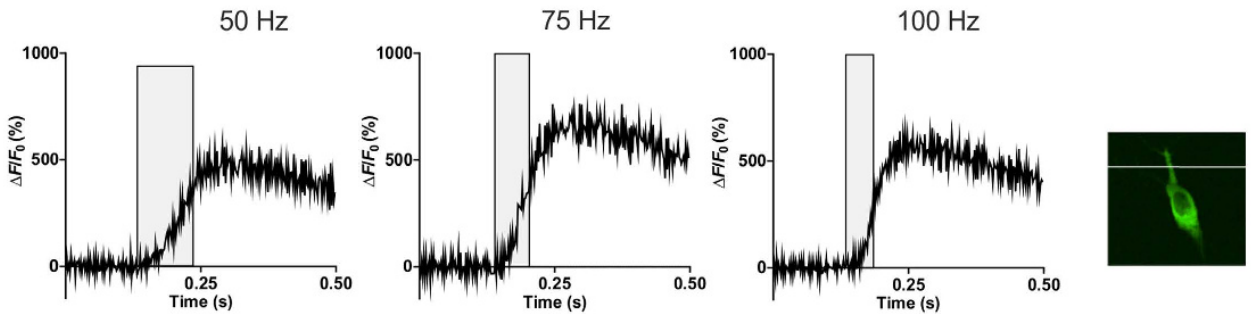

C
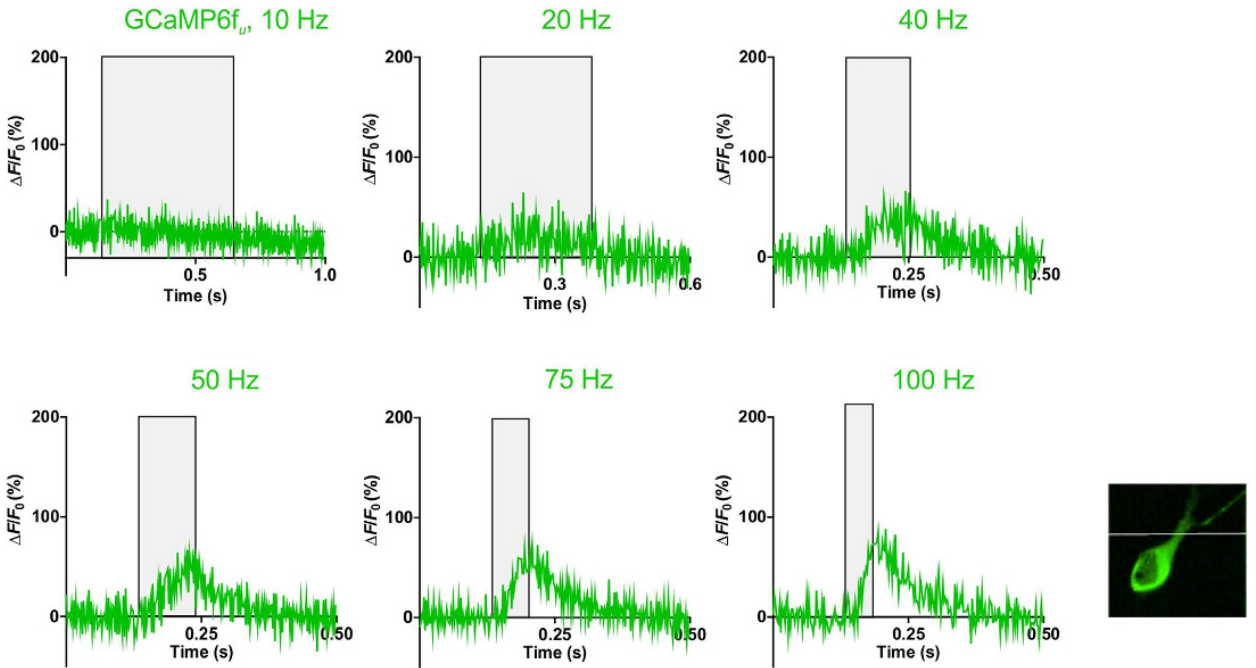

Figure 4. $\mathrm{Ca}^{2+}$ response of GCaMP6f and GCaMP6f $\mathrm{f}_{u}$ in ATP-stimulated HEK293T cells and post-synaptic CA1 neurons in hippocampal slices. (a) $\mathrm{Ca}^{2+}$ transients were triggered by exposure of HEK293T cells to $100 \mu$ M ATP. Time courses of response of GCaMP6f and GCaMP6f $f_{u}$ are shown. $t_{1 / 2}$ for GCaMP6f $f_{u} 2.3 \pm 0.04 \mathrm{~s}$ was significantly different from that for GCaMP6f $(9.4 \pm 0.2 \mathrm{~s})$. (b) $\mathrm{Ca}^{2+}$ response kinetics in post-synaptic CA1 neurons in hippocampal slices of GCaMP $6 \mathrm{f}\left(28^{\circ} \mathrm{C}\right)$ to stimulation by 5 action potentials (AP-s). Grey shaded areas indicate the duration of stimulation. GCaMP6f stimulated at ( 3 cells, $n$ number of recordings in brackets) $10 \mathrm{~Hz}(\mathrm{n}=28), 20 \mathrm{~Hz}(\mathrm{n}=28), 40 \mathrm{~Hz}(\mathrm{n}=29), 50 \mathrm{~Hz}(\mathrm{n}=27), 75 \mathrm{~Hz}(\mathrm{n}=30)$ and $100 \mathrm{~Hz}(\mathrm{n}=19)$; (c) GCaMP6f $\mathrm{f}_{u}$ stimulated (4 cells, $\mathrm{n}$ number of recordings in brackets) at $10 \mathrm{~Hz}(\mathrm{n}=29), 20 \mathrm{~Hz}(\mathrm{n}=30), 40 \mathrm{~Hz}$ $(\mathrm{n}=29), 50 \mathrm{~Hz}(\mathrm{n}=29), 75 \mathrm{~Hz}(\mathrm{n}=30)$ and $100 \mathrm{~Hz}(\mathrm{n}=26)$. The achieved maximum $\Delta F / F_{0}$ values are plotted against time. Inset images: representative images baseline expression of GCaMP6f and GCaMP6 $\mathrm{f}_{u}$ in CA1 pyramidal neurons with white line in the position of the line scan. 
a

\begin{tabular}{|c|c|c|c|c|c|c|c|c|}
\hline & RS20 & cpEGFP & linker & \multicolumn{5}{|c|}{$\mathrm{CaM}$} \\
\hline GCaMP3 & W43 & & R303 & A317 & D380 & S383 & R392 & D395 \\
\hline $\mathrm{GCaMP}_{\text {fast }}$ & W43Y & & & & & & & D395A \\
\hline GCaMP5G & & & T302L R303P & & D380Y & & & \\
\hline GCaMP6f & & & T302L R303P & A317E & D380Y T381R & S383T & R392G & \\
\hline $\mathrm{GCaMP} \mathrm{ff}_{u}$ & W43Y & & T302L R303P & A317E & D380Y T381R & S383T & R392G & D395A \\
\hline
\end{tabular}

b
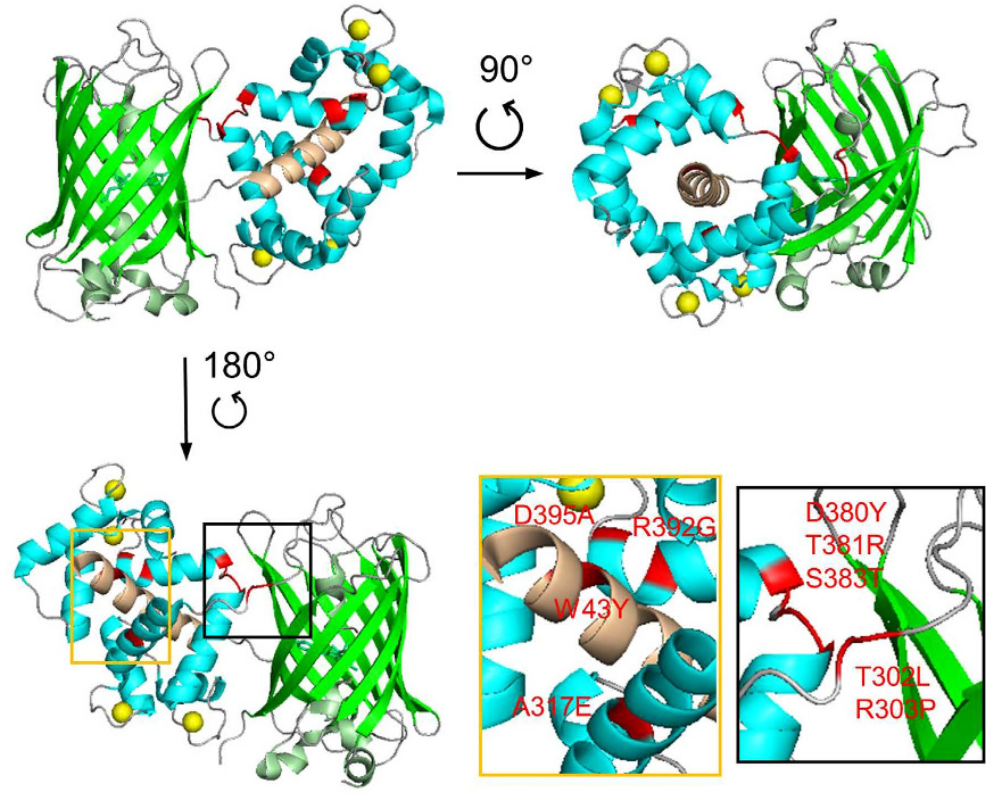

C

$$
\text { "open" conformation }
$$

d
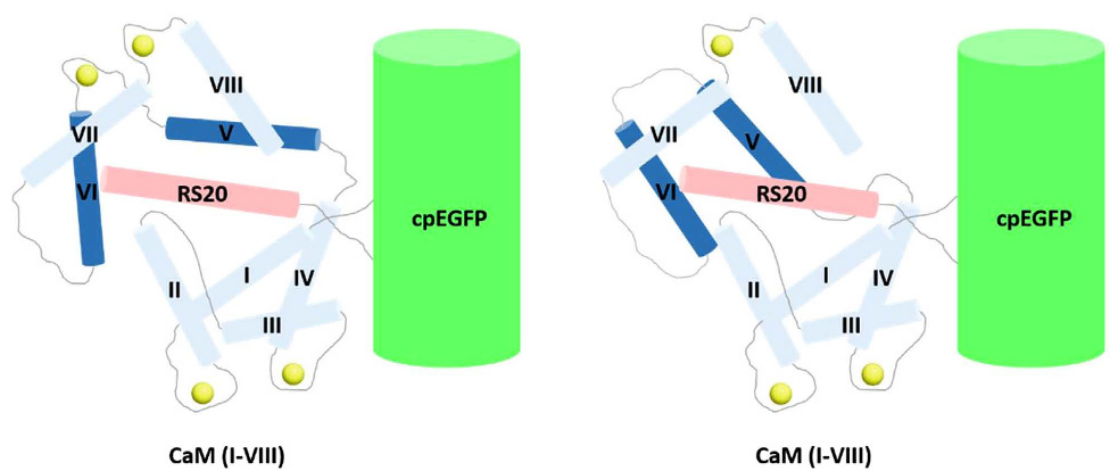

Figure 5. Comparison of fast GCaMP probes $\left(\mathrm{GCaMP}_{\text {fast }}\right.$ and GCaMP6f $\left.\mathrm{f}_{u}\right)$ and their parent variants (GCaMP3 and GCaMP6f). (a) Position of the mutations that gave rise to GCaMP $3_{\text {fast }}$ and GCaMP6f $\mathrm{f}_{u}$ variants, relative to GCaMP3. (b) Crystal structure of monomeric GCaMP6m in a $\mathrm{Ca}^{2+}$-bound form with cpEGFP (green), $\mathrm{Ca}^{2+}$ ions (yellow), CaM (blue) and the RS20 peptide (light brown) (adapted from Ding et al., ${ }^{27} \mathrm{PDB}$ $3 \mathrm{WLD})$. The amino acid residues highlighted in red are those that generated GCaMP6f $f_{u}$ relative to GCaMP3. Schematic representation of (c) $\mathrm{Ca}^{2+}$-bound GCaMP3/GCaMP6f showing "open" conformation of EF-hand 3 (helices V and VI); (d) $\mathrm{Ca}^{2+}$-bound GCaMP $3_{\text {fast }} / \mathrm{GCaMP}_{\mathrm{u}}$ showing "closed" conformation of disabled EFhand 3 (helices V and VI).

increased brightness and dynamic range in GCaMP5G and GCaMP6f $\mathrm{f}^{3,19}$. The gain of brightness is likely due to a structural rearrangement involving these crucial hydrophobic residues not present in GCaMP3 as described below. These mutations decrease the flexibility of the cpEGFP - CaM helix I linker, through interaction between helix IV-V and cpEGFP - CaM helix I linkers. Specifically, the T302L, R303P, D380Y mutations play the most significant roles in ordering/positioning cpEGFP - CaM helix I linker, as GCaMP5G is almost as bright as GCaMP6f. The R303P mutation decreases flexibility and increases order in the cpEGFP - CaM helix I linker, thus positioning the mutated L302 and Y380 hydrophobic sidechains in proximity allowing them to form tertiary interactions. 
In GCaMP6f, the cpEGFP - CaM helix I and helix IV-V linkers interact and stabilise one another. Thus the three mutations position the cpEGFP - CaM helix I linker with respect to RS-20 peptide - cpEGFP linker stabilising cpEGFP folding. In contrast, the T302, R303 and D380 residues, originally present in GCaMP3, allow the cpEGFP - CaM helix I linker to be more dynamic, thus increasing entropic penalty for cpEGFP folding in GCaMP3 with respect to GCaMP6f. In GCaMP3, the cpEGFP - CaM helix I linker and helix IV-V linkers are dynamic, reducing the stability of folded cpEGFP, explaining/causing its reduced brightness, which is the measure of the fraction of folded cpEGFP. The D395A mutation, introduced in GCaMP3 $3_{\text {fast }}$ and GCaMP6f $\mathrm{f}_{u}$, prevents $\mathrm{Ca}^{2+}$ binding to the EF-3 site (flanked by helices V and VI), which thus, rather than being in an "open" conformation as in $\mathrm{Ca}^{2+}$-bound GCaMP-s (Fig. 5c), is expected to remain in "closed" conformation (Fig. 5d). Thus, the cpEGFP - CaM helix I linker is imperfectly poised with respect to RS-20 peptide - cpEGFP linker, cpEGFP folding is thus destabilised and the brightness is reduced in GCaMP3 ${ }_{\text {fast }}$ and GCaMP6 $\mathrm{f}_{u}$. In GCaMP3, the CaM EF-hand 3 adopts "open" conformation, but the cpEGFP - CaM helix I linker remains dynamic, hence cpEGFP folding is still destabilised explaining its similar brightness to GCaMP $3_{\text {fast }}$ and GCaMP6f $f_{u}$. Closing the CaM EF-hand 3 conformation by the W43Y/D395A mutation thus has the equivalent effect on cpEGFP folding as destabilising the cpEGFP - CaM helix I linker.

We observed that GCaMP-type GECI have a limiting response rate that is independent of $\left[\mathrm{Ca}^{2+}\right]^{25}$. Moreover, the $\mathrm{Ca}^{2+}$ rise kinetics of GCaMP6s and GCaMP6f revealed complex biphasic processes: although at $20^{\circ} \mathrm{C}$ GCaMP6s and GCaMP6f have $20 \mathrm{~ms}$ and $2 \mathrm{~ms}$ response times, the amplitude of their fast phase diminishes with increasing temperature, thus presenting as slow indicators, at $37^{\circ} \mathrm{C}$. In contrast, GCaMP $3_{\text {fast }}$ and GCaMP $6 \mathrm{f}_{u}$ have greatly improved fluorescence rise time of $1 \mathrm{~ms} t_{1 / 2}$ at $37^{\circ} \mathrm{C}$. By targeting the CaM - RS20 peptide interface, GCaMP3 RS09 and GCaMP6f RS09 had improved decay $t_{1 / 2}-\mathrm{s}$ of 25 and $20 \mathrm{~ms}\left(37^{\circ} \mathrm{C}\right)^{23,24}$, compared to decay $t_{1 / 2}$-s of GCaMP3 with $147 \mathrm{~ms}$ and GCaMP6f with $71 \mathrm{~ms}$. However GCaMP $3_{\text {fast }}^{25}$ and GCaMP6f $\mathrm{f}_{u}$ have the fastest decay with a $t_{1 / 2}$ of $3 \mathrm{~ms}$, at $37^{\circ} \mathrm{C}$.

The fluorescence response kinetics of GCaMP-s have been modelled from the stopped-flow data. Previously a model has been put forward in which the $\mathrm{Ca}^{2+}$ response rate depends on the $\mathrm{Ca}^{2+}$ step: a small $\mathrm{Ca}^{2+}$ step results in slow binding to the $\mathrm{C}$-lobe followed by fast binding to the low affinity the $\mathrm{N}$-lobe; in contrast, a large step in $\mathrm{Ca}^{2+}$ evokes fast $\mathrm{Ca}^{2+}$ response via N-lobe binding and in this mode $\mathrm{C}$-lobe binding is not required for the fluorescent state $^{24}$. Our modeling studies reveal a different mechanism: first, that although $\mathrm{N}$-lobe $\mathrm{Ca}^{2+}$ binding is necessary for $\mathrm{Ca}^{2+}$-induced fluorescence enhancement, it is not sufficient for the fluorescence response which also requires $\mathrm{C}$-lobe $\mathrm{Ca}^{2+}$-binding; second, the limiting rate of the probes is determined by the $\mathrm{Ca}^{2+}$ association kinetics of the $\mathrm{C}$-terminal $\mathrm{CaM}$ lobe in conjunction with the re-equilibration of the two postulated fluorescent states. $\mathrm{Ca}^{2+}$ binding is of lower affinity to the CaM N-lobe than to the C-lobe, however, in the presence of a target peptide the $\mathrm{Ca}^{2+}$ affinity of the $\mathrm{N}$-lobe may be similar or higher than that of the $\mathrm{C}-\mathrm{lobe}^{28}$. The $\mathrm{Ca}^{2+}$ binding kinetics of CaM-peptide complexes have not been determined, thus the rate constants for CaM were used ${ }^{29}$. $\mathrm{Ca}^{2+}$ dissociation from $\mathrm{CaM}$ and its peptide complexes is commonly thought to occur in pairs of $\mathrm{Ca}^{2+}$. Whether a single or double exponential process is observed for the fluorescence decay depends on the rates by which the putative two- and four- $\mathrm{Ca}^{2+}$ saturated states convert into each other and decay ${ }^{26}$.

Temperature dependencies of the $\mathrm{Ca}^{2+}$ rise kinetics suggest complex underlying activation thermodynamics. Positive, neutral and negative temperature-induced rate changes all occur, indicating that the EF-hand and peptide mutations have sensitively affected the balance of entropy and enthalpy gains. Favourable dehydration of hydrophobic surfaces results in entropy-driven activation and a positive temperature coefficient ${ }^{30}$. The lack of temperature dependence of the rates, e.g. GCaMP6f fast on-rate, is consistent with the limiting fast rate being $\mathrm{Ca}^{2+}$ binding, a diffusion limited process. Negative temperature coefficients observed for EF-3 and EF-3:4 mutants likely stem from less hydrophobic interaction and hence less positive entropy and more negative enthalpy change deriving from CaM C-lobe interaction with peptide in the absence of EF-3 or EF- $4 \mathrm{Ca}^{2+}$ binding and weakened binding of peptide due to $\mathrm{W}$ to $\mathrm{Y}$ substitution. Reduced brightness appears to be a trade-off for fast kinetics, presenting an opportunity for future improvements. While the $\mathrm{EF}-3 \mathrm{Ca}^{2+}$ binding site is responsible for brightness, the EF-4 site is the guardian of cooperativity of the C-terminal CaM lobe for $\mathrm{Ca}^{2+}$ when binding the RS20 target peptide.

A commonly observed property of cpEGFP- and CaM-peptide interaction-based GECI is high cooperativity for $\mathrm{Ca}^{2+}$, often showing an all-or-none response to $\mathrm{Ca}^{2+}$ elevation as revealed by stopped-flow kinetic experiments on GCaMP ${ }_{\text {fast }}{ }^{25}$ and GCaMP $6 \mathrm{f}_{u}$. Fast all-or-none response to small changes in $\left[\mathrm{Ca}^{2+}\right.$ ] would make GCaMP-type probes well suited for spike detection, however the current fast variants have insufficient brightness. RCaMP2 and some mGCaMP3, mG-GECO and mGEM-GECO have slower kinetics and reduced cooperativity for $\mathrm{Ca}^{2+}$ with Hill coefficients of $1-1.7^{16,25}$, possibly by a combination of negatively and positively cooperative molecular responses, making them potentially useful for quantifying $\left[\mathrm{Ca}^{2+}\right]$ changes in cells.

While the EF- 3 single mutation raises the $K_{\mathrm{d}}$ to low $\mu \mathrm{M}$, the EF-4 single and the EF-3:4 double mutations break up the affinity into two components, one with a $K_{\mathrm{d}}$ of low $\mu \mathrm{M}$ and one in the $\mathrm{mM}$ range with most of the fluorescence enhancement occurring in $\mathrm{mM} \mathrm{Ca}^{2+}$. In the kinetic modeling only high affinity sites with $\mu \mathrm{M} K_{\mathrm{d}}$ are considered. As there are only two $\mathrm{Ca}^{2+}$ binding sites in the EF-3:4 mutants, the low, $\mathrm{mM}$ affinity $\mathrm{Ca}^{2+}$ binding is likely attributable to the mutated EF-hand 3 (necessary for high brightness and dynamic range) which in the presence of the RS20 target peptide may acquire such affinity for $\mathrm{Ca}^{2+}$. EF-3:4 double EF-hand mutant probes with $\mathrm{mM} K_{\mathrm{d}}$-s may be for suitable for intra-organelle and extracellular applications, after further improvements to their brightness and dynamic range. mGCaMP6s EF-3:4 is the most promising low affinity probe with a $500 \mu \mathrm{M}$ $K_{\mathrm{d}}$ and a 19 -fold $\mathrm{Ca}^{2+}$-induced fluorescence enhancement $\left(20^{\circ} \mathrm{C}\right)$, comparing favourably with CEPIA ${ }^{14}$.

The success of monitoring intracellular $\mathrm{Ca}^{2+}$ dynamics requires that the detection range of the probe is appropriate for the size and time course of the $\left[\mathrm{Ca}^{2+}\right]$ transient. In the conditions of ionomycin stimulation, the expected peak $\left[\mathrm{Ca}^{2+}\right.$ ] was 0.4 to $0.8 \mu \mathrm{M}^{31}$. GCaMP6s with $K_{\mathrm{d}}$ of $110 \mathrm{nM}, 5-10$-fold lower than the peak of the $\left[\mathrm{Ca}^{2+}\right]$ transient, was thus expected to be mostly saturated and thus signal such a transient with close to its 
maximum dynamic range. However, at resting $\left[\mathrm{Ca}^{2+}\right]$ of $\sim 50-80 \mathrm{nM}$, there is already considerable $\mathrm{Ca}^{2+}$ binding to such a probe. As a result of the two parameters the measured $\Delta F / F_{0}$ of 18 for GCaMP6s in ionomycin stimulated HEK293T cells is a reasonable value.

Regarding the kinetics of $\mathrm{Ca}^{2+}$ indicators, it is evident that low $K_{\mathrm{d}}$ probes with slow response report slower intracellular $\mathrm{Ca}^{2+}$ dynamics than higher $K_{\mathrm{d}}$ probes with fast responses. GCaMP6f $\mathrm{f}_{u}$ and mGCaMP6f RS-1 EF-4 both showed 4-fold faster $\mathrm{Ca}^{2+}$ decay in response to ATP stimulation than GCaMP6f. By its two-fold faster response rate, in cardiac myocytes, $\mathrm{GCaMP} 3_{\text {fast }}$ revealed removal of $\mathrm{Ca}^{2+}$ and return to resting intracellular levels between each beat, a phenomenon not clearly resolved by GCaMP $6 \mathrm{f}^{25}$

It transpires that the brightness and dynamic range of GCaMP6f $\mathrm{f}_{u}$ are not sufficient for the detection of the post-synaptic dendritic $\left[\mathrm{Ca}^{2+}\right]$ elevation evoked by a single AP. Although the kinetic properties of GCaMP6f would allow the separation of individual AP-s even at $100 \mathrm{~Hz}$, the actual $\mathrm{Ca}^{2+}$ transient reveals an integrated $\mathrm{Ca}^{2+}$ response, raising the possibility that the $\mathrm{Ca}^{2+}$ dynamics associated with AP firing limit the use of $\mathrm{Ca}^{2+}$ as an indicator of neuronal activity.

Although unable to detect single AP-s, GCaMP6f $f_{u}$ with its fast rise and decay kinetics may still be useful for the detection of repeated AP-s with between-train intervals of tens rather than hundreds of milliseconds. The $\mathrm{Ca}^{2+}$ induced fluorescence rise times of GCaMP3 RS09 and GCaMP6f RS09 remained slow in physiological experiments ${ }^{23,24}$. In contrast, the $\mathrm{Ca}^{2+}$ rise rates following a train of $5 \mathrm{AP}$-s in organotypic hippocampal slices reported by the GCaMP6f $f_{u}$ and mGCaMP6f RS-1 EF-4 probes were markedly faster than GCaMP6f. When comparing the novel variant $\mathrm{GCaMP}_{4}$ to $\mathrm{GCaMP}_{\text {fast }}{ }^{25}$, though they show similar kinetic properties, GCaMP6f $f_{u}$ which has a 3 -fold lower $K_{\mathrm{d}}(0.89 \mu \mathrm{M})$ compared to GCaMP $3_{\text {fast }}(2.8 \mu \mathrm{M})$ is more sensitive to small $\mathrm{Ca}^{2+}$ con- $^{2}$ centration changes and hence more suitable for $\mathrm{Ca}^{2+}$ imaging in neurons. Improved brightness and fluorescence dynamic range would help make GCaMP6f $f_{u}$ with its ultrafast kinetics a useful physiological tool.

\section{Materials and Methods}

Materials. GCaMP6s and GCaMP6f plasmids were a gift from Douglas Kim (Addgene plasmid \#40753 and $\# 40755$, respectively $)^{19}$. pET41a and pEGFP-N1 vectors were obtained from Novagen and Clontech, respectively. XL10-Gold and BL21 (DE3) Gold cells were purchased from Invitrogen. Restriction enzymes were obtained from New England Biolabs and T4 DNA ligase from Fermentas.

Generation of improved GCaMP6 probes. The strategy previously developed and described for the improvement of GCaMP3 probes was followed to design, generate and purify mutants of GCaMP6s and GCaMP6f probes $^{19}$. For protein expression, GCaMP6s and GCaMP6f were subcloned from pGP-CMV backbone into pET41a bacterial expression vector. Mutant GECI were generated by site-directed mutagenesis of CaM EF-hands and RS20 peptide as previously described ${ }^{25}$. GCaMP6s and GCaMP6f and their mutants were overexpressed as GST-fusion proteins overnight at $20^{\circ} \mathrm{C}$ in the presence of $0.5 \mathrm{mM}$ IPTG in E. Coli BL21(DE3) Gold cells. Cells were lysed by sonication and clarified lysates were purified by a single-step GST-chromatography (GSTrap, ÄKTA Purifier, GE Healthcare) in $50 \mathrm{mM} \mathrm{Na}^{+}$-HEPES pH 7.5, $200 \mathrm{mM} \mathrm{NaCl}$ and $10 \mathrm{mM}$ glutathione, at $4{ }^{\circ} \mathrm{C}$. Purity of the eluted fractions was determined by SDS-PAGE $(6.4 \%-20 \%$ acrylamide/bisacrylamide gradient). Protein concentrations were measured spectroscopically at $280 \mathrm{~nm}$ by a Nanodrop 1000 spectrophotometer (Thermo Scientific) using an $\varepsilon_{\mathrm{o}}$ value of $76585 \mathrm{M}^{-1} \mathrm{~cm}^{-1}$ calculated from the amino acid composition for GCaMP6s, GCaMP6f and their EF-hand mutants and $\varepsilon_{\mathrm{o}}$ of $70710 \mathrm{M}^{-1} \mathrm{~cm}^{-1}$ for the RS-1 mutants ${ }^{32}$.

Quantum yield determination. Protein concentrations were adjusted such that the absorbance at the excitation wavelength $(490 \mathrm{~nm})$ was between 0.001 and 0.1 . A series of dilutions was prepared in a buffered solution ( $50 \mathrm{mM}$ HEPES-K ${ }^{+} \mathrm{pH} 7.5,100 \mathrm{mM} \mathrm{KCl}, 2 \mathrm{mM} \mathrm{MgCl}_{2}$ with either $5 \mathrm{mM} \mathrm{EGTA}$ or $1 \mathrm{mM} \mathrm{CaCl}_{2}$ ) and the fluorescence spectra were recorded on a Fluorolog3 spectrofluorimeter (Horiba Scientific) at $20^{\circ} \mathrm{C}$. The quantum yield measured for GCaMP6f in $\mathrm{Ca}^{2+}$-saturated buffer was used as a reference $(\Phi=0.59)^{19}$. Data were plotted as integrated fluorescence intensity as a function of absorbance and fitted by linear regression. The gradient of the plots for the reference GCaMP6f and the protein to be measured are termed $S_{\mathrm{GCaMP} 6 \mathrm{f}}$ and $\mathrm{S}_{\text {protein, }}$, respectively. Quantum yields were obtained using the following equation: $\Phi_{\text {protein }}=\Phi_{\mathrm{GCaMP6f}} \times\left(\mathrm{S}_{\text {protein }} / \mathrm{S}_{\mathrm{GCaMP6s}}\right)$.

pH sensitivity of GCaMP6s and GCaMP6f-derived proteins. To determine the apparent pKa for each protein in the presence and absence of $\mathrm{Ca}^{2+}$, a series of buffers with $0.5 \mathrm{pH}$ unit intervals were prepared. Depending on their respective $\mathrm{pH}$ buffering range, appropriate buffer was used for the measurements (MES for $\mathrm{pH}$ 6-6.5, HEPES for $\mathrm{pH} 7-8$, TRIS for $\mathrm{pH} 8.5-9$ and CAPS for $\mathrm{pH} 10)$. The $\mathrm{pH}$ titrations were performed by recording fluorescence spectra of $1 \mu \mathrm{M}$ protein in $\mathrm{Ca}^{2+}$-free $(50 \mathrm{mM}$ buffer, $100 \mathrm{mM} \mathrm{KCl}, 2 \mathrm{mM} \mathrm{MgCl}, 2 \mathrm{mM}$ BAPTA) or $\mathrm{Ca}^{2+}$-saturated ( $50 \mathrm{mM}$ buffer, $100 \mathrm{mM} \mathrm{KCl}, 2 \mathrm{mM} \mathrm{MgCl}, 1 \mathrm{mM} \mathrm{CaCl}$ ) conditions (Fluorolog3, Horiba). BAPTA was chosen over EGTA as $\mathrm{Ca}^{2+}$ chelator because of its stable affinity for $\mathrm{Ca}^{2+}$ over the $\mathrm{pH}$ range $^{33}$. All titrations were performed in triplicates and expressed as normalised mean \pm s.e.m.

Determination of free $\mathrm{Ca}^{2+}$ concentrations $\left(\left[\mathrm{Ca}^{2+}\right]\right) . \quad\left[\mathrm{Ca}^{2+}\right]$ were calculated using the $\mathrm{Ca} / \mathrm{Mg} / \mathrm{ATP} / \mathrm{EGTA}$ Calculator v1 constants from Schoenmakers' Chelator program for experiments at $20^{\circ} \mathrm{C}$ and $37^{\circ} \mathrm{C}^{34}$.

Equilibrium $\mathrm{Ca}^{2+}$ binding. $\mathrm{Ca}^{2+}$ affinity assays of GECI and mGECI were performed by continuous titration using an automated syringe pump (ALADDIN 1000, WPI) at $20^{\circ} \mathrm{C}$ or $37^{\circ} \mathrm{C}$. GECI proteins at $50-100 \mathrm{nM}$ concentration $\left(50 \mathrm{mM} \mathrm{K}^{+}\right.$-HEPES $\mathrm{pH} 7.5,100 \mathrm{mM} \mathrm{KCl}, 2 \mathrm{mM} \mathrm{MgCl}_{2}$ and $5 \mathrm{mM} \mathrm{EGTA}$ ) were titrated with $325 \mathrm{mM}$ $\mathrm{CaCl}_{2}$ at a $10 \mu \mathrm{L} / \mathrm{min}$ flow rate in a stirred $3 \mathrm{~mL}$ cuvette. Fluorescence was measured at $492 \mathrm{~nm}$ excitation and $515 \mathrm{~nm}$ emission wavelengths on a Fluorolog3 spectrofluorimeter (Horiba Scientific). Fluorescence records were corrected for dilution and photobleaching. Data were normalised and expressed as bound fraction. Half-maximal 
brightness concentration $\left(K_{\mathrm{d}}\right)$ and cooperativity for $\mathrm{Ca}^{2+}(n)$ were obtained by fitting the data to the Hill equation using GraphPad Prism 6 software. All titrations were performed at least in triplicates and expressed as mean \pm s.e.m.

Stopped-flow fluorimetry. $\mathrm{Ca}^{2+}$ association and dissociation kinetic experiments of GCaMP6s and GCaMP6f proteins were carried out on a Hi-Tech Scientific SF-61DX2 stopped-flow system at temperatures ranging from $15^{\circ} \mathrm{C}$ to $37^{\circ} \mathrm{C}$. Fluorescence excitation was set to $492 \mathrm{~nm}$ and fluorescence emission was collected using a $530 \mathrm{~nm}$ cut-off filter. Experiments were performed at least in triplicates and three sets of data were averaged for analysis. Data were fitted to either a single or a double exponential to obtain the rise or decay rates using KinetAssyst software.

Association kinetics. The solution containing $1 \mu \mathrm{M}$ protein in $50 \mathrm{mM} \mathrm{K}^{+}$-HEPES $\mathrm{pH} 7.5,100 \mathrm{mM} \mathrm{KCl}, 2 \mathrm{mM}$ $\mathrm{MgCl}_{2}$ and $10 \mathrm{mM}$ EGTA was rapidly mixed (1:1) with $50 \mathrm{mM} \mathrm{K}^{+}$-HEPES pH 7.5, $100 \mathrm{mM} \mathrm{KCl,} 2 \mathrm{mM} \mathrm{MgCl}_{2}$ and $10 \mathrm{mM}$ EGTA containing increasing $\left[\mathrm{Ca}^{2+}\right]$ concentrations (concentrations in the mixing chamber). For the determination of temperature dependence of $\mathrm{Ca}^{2+}$ association rates, protein samples at $1 \mu \mathrm{M}$ concentration were mixed as above with saturating $\mathrm{Ca}^{2+}\left(7.5-20 \mu \mathrm{M}\right.$ final $\left[\mathrm{Ca}^{2+}\right]$ in the mixing chamber).

Dissociation kinetics. The solution containing $1 \mu \mathrm{M}$ protein in $50 \mathrm{mM} \mathrm{K}^{+}$-HEPES, $100 \mathrm{mM} \mathrm{KCl}, 2 \mathrm{mM} \mathrm{MgCl}_{2}$, pH 7.5 with saturating $\mathrm{Ca}^{2+}(0.5 \mathrm{mM})$ was rapidly mixed (1:1) with $50 \mathrm{mM} \mathrm{K}^{+}$-HEPES, $100 \mathrm{mM} \mathrm{KCl,} 2 \mathrm{mM}$ $\mathrm{MgCl}_{2}, 10 \mathrm{mM}$ EGTA pH 7.5 (concentrations in the mixing chamber).

Cloning of $\mathrm{mGECl}$ into a mammalian expression vector. For expression in eukaryotic cells, the GCaMP6s and GCaMP6f mutant DNAs were subcloned from pET41a into pEGFP-N1 vectors by restriction-ligation using BglII and NotI restriction enzymes and T4 DNA ligase following manufacturer's protocol. During this process, the egfp initially present in the pEGFP-N1 vector was replaced by the gcamp6 genes (without the GST tag).

Imaging of GCaMP6f variants in HEK293T cells. Cells were cultured in DMEM containing $10 \%$ fetal bovine serum and $1 \%$ penicillin/streptomycin at $37^{\circ} \mathrm{C}$ and $5 \% \mathrm{CO}_{2}$.

Ionomycin stimulation. Transfection of cells was carried out on $10 \mathrm{~mm}$ diameter coverslips with $0.6 \mu \mathrm{g}$ DNA and $2.5 \mu \mathrm{L}$ Lipofectamine 2000 in $100 \mu \mathrm{L} \mathrm{OptiMem}{ }^{\circledR}$ for $1 \mathrm{~h}$ at $37^{\circ} \mathrm{C}$. Cells were imaged $16-24 \mathrm{~h}$ post-transfection in $10 \mathrm{mM}$ HEPES pH 7.5, $145 \mathrm{mM} \mathrm{NaCl}, 2.5 \mathrm{mM} \mathrm{KCl}, 1 \mathrm{mM} \mathrm{MgCl}, 10 \mathrm{mM}$ glucose and $2 \mathrm{mM}$ $\mathrm{CaCl}_{2}$. For determination of the fluorescence dynamic range, cells were imaged before and after stimulation by $10 \mu \mathrm{M}$ ionomycin at $20^{\circ} \mathrm{C}$. Imaging was performed with a Leica SP1 confocal microscope using a HCX ApoL $40 \times 0.8 \mathrm{NA}$ water immersion objective, images were acquired at $512 \times 512$ pixel size. Experiments were performed at least in triplicates, elliptical regions of interest (ROI) were selected and data were analysed using Leica Application Suite.

ATP stimulation. HEK293T cells were transfected with GCaMP6f variants using Fugene HD following the manufacturer's recommendations. Imaging was performed $16-24 \mathrm{~h}$ post-transfection at $37^{\circ} \mathrm{C}(\mathrm{OKO}$ lab incubation chamber) in a 35-mm glass bottom dish (MatTek) with a 3i Marianas spinning-disk confocal microscope equipped with a Zeiss AxioObserver Z1, a $40 \times 1.3 \mathrm{NA}$ oil immersion objective and a $3 \mathrm{i}$ Laserstack as excitation light source $(488 \mathrm{~nm})$. Emitted light was collected through a single bandpass filter (Yokogawa CSU-X filter wheel) onto a CMOS camera (Hamamatsu, ORCA Flash 4.0; $1152 \times 1656$ pixels). Cells were stimulated with $100 \mu \mathrm{M}$ ATP and images were collected at $1 \mathrm{~s}$ intervals for 40 seconds. Elliptical ROI were stacked using ImageJ program. Data obtained from 14-24 cells was plotted and analysed on GraphPad Prism 6. Fluorescence decay times were determined from single exponential fits to the data.

Two-photon imaging of GCaMP6f, GCaMP6f $f_{u}$ and mGCaMP6 RS-1 EF-4 in hippocampal slices. Sprague Dawley rats were purchased from Charles River. All experiments were conducted in accordance with the Canadian Council on Animal Care standards and guidelines, with approval of the Dalhousie University Committee on Laboratory Animals. Transverse organotypic hippocampal slices $(350 \mu \mathrm{m})$ were made from brains of rat pups aged 6 to 8 postnatal days humanely killed by Schedule 1 procedure (anesthetic (ketamine) overdose followed by decapitation) and cultured on Millicell CM membranes for 5 to 6 days ${ }^{35,36}$. Hippocampal slices were transfected using biolistics as described previously ${ }^{37}$. Slice preparations were transferred to a recording chamber and superfused at $28^{\circ} \mathrm{C}$ with artificial cerebrospinal fluid (containing $120 \mathrm{mM} \mathrm{NaCl}, 3 \mathrm{mM} \mathrm{KCl}, 2 \mathrm{mM} \mathrm{MgSO}_{4}$, $4 \mathrm{mM} \mathrm{CaCl}_{2}, 1.2 \mathrm{mM} \mathrm{NaH}_{2} \mathrm{PO}_{4}$ and $11 \mathrm{mM}$ glucose) saturated with a gas mixture of $95 \% \mathrm{O}_{2} / 5 \% \mathrm{CO}_{2}$.

An upright epifluorescence microscope (Olympus BX51WI) with a $60 \times 1.0$ NA IR water immersion objective (Olympus) and an MRC1024MP (Bio-Rad Microscience, Hemel Hampstead, United Kingdom) laser scanner with nondescanned photomultiplier tube detectors were used to view slices. Two-photon imaging was carried out 1-4 days post-transfection using a MaiTai titanium sapphire laser) at $930 \mathrm{~nm}$.

Action potentials were evoked and recorded in expressing CA1 pyramidal neurons using a sharp intracellular electrode (60-80 M $\Omega$ ) filled with $3 \mathrm{M} \mathrm{KCl}$ in $20 \mathrm{mM}$ 2-[4-(2-hydroxyethyl)piperazin-1-yl]ethanesulfonic acid. Line scans taken at $2 \mathrm{~ms}$ interval across proximal apical dendrites were collected to determine the calcium transients measured as $\Delta F / F_{0}$ (defined as $\Delta F / F_{0}=100\left(F_{\text {transient }}-F_{\text {initial }}\right) /\left(F_{\text {initial }}-F_{\text {background }}\right)$ corresponding to 5 AP-s evoked by brief depolarizing current injection at frequencies between $10-100 \mathrm{~Hz}$ via a Multiclamp $700 \mathrm{~B}$ amplifier (Molecular Devices, California). $\mathrm{Ca}^{2+}$ decay kinetics of GCaMP6 variants were determined by monitoring fluorescence changes evoked by $5 \mathrm{APs}$ at $100 \mathrm{~Hz}$.

Electrophysiological and imaging data were collected and analysed with software from AxoGraph (AxoGraph Scientific, Sydney, Australia), LaserSharp (Bio-Rad Microscience) and Image ${ }^{38}$. 


\section{References}

1. Fernandez-Alfonso, T. et al. Monitoring synaptic and neuronal activity in 3D with synthetic and genetic indicators using a compact acousto-optic lens two-photon microscope. J. Neurosci. Methods. 222, 69-81 (2014).

2. Akerboom, J. et al. Crystal structures of the GCaMP calcium sensor reveal the mechanism of fluorescence signal change and aid rational design. J. Biol. Chem. 284, 6455-6464 (2009).

3. Akerboom, J. et al. Optimization of a GCaMP calcium indicator for neural activity imaging. J. Neurosci. 32, 13819-13840 (2012).

4. Hendel, T. et al. Fluorescence changes of genetic calcium indicators and OGB-1 correlated with neural activity and calcium in vivo and in vitro. J. Neurosci. 28, 7399-7411 (2008).

5. Muto, A. et al. Genetic visualization with an improved GCaMP calcium indicator reveals spatiotemporal activation of the spinal motor neurons in zebrafish. Proc. Natl. Acad. Sci. USA 108, 5425-5430 (2011).

6. Nakai, J., Ohkura, M. \& Imoto, K. A high signal-to-noise $\mathrm{Ca}^{2+}$ probe composed of a single green fluorescent protein. Nat. Biotechnol. 19, 137-141 (2001).

7. Ohkura, M., Matsuzaki, M., Kasai, H., Imoto, K. \& Nakai, J. Genetically encoded bright $\mathrm{Ca}^{2+}$ probe applicable for dynamic Ca ${ }^{2+}$ imaging of dendritic spines. Anal. Chem. 77, 5861-5869 (2005).

8. Souslova, E. A. et al. Single fluorescent protein-based $\mathrm{Ca}^{2+}$ sensors with increased dynamic range. BMC. Biotechnol. 7, 37 (2007).

9. Tallini, Y. N. et al. Imaging cellular signals in the heart in vivo: Cardiac expression of the high-signal $\mathrm{Ca}^{2+}$ indicator GCaMP2. Proc. Natl. Acad. Sci. USA 103, 4753-4758 (2006).

10. Tian, L. et al. Imaging neural activity in worms, flies and mice with improved GCaMP calcium indicators. Nat. Methods. 6, 875-881 (2009).

11. Wang, Q., Shui, B., Kotlikoff, M. I. \& Sondermann, H. Structural basis for calcium sensing by GCaMP2. Structure. 16, 1817-1827 (2008).

12. Baird, G. S., Zacharias, D. A. \& Tsien, R. Y. Circular permutation and receptor insertion within green fluorescent proteins. Proc. Natl. Acad. Sci. USA 96, 11241-11246 (1999)

13. Zhao, Y. et al. An expanded palette of genetically encoded $\mathrm{Ca}^{2+}$ indicators. Science. 333, 1888-1891 (2011).

14. Suzuki, J. et al. Imaging intraorganellar $\mathrm{Ca}^{2+}$ at subcellular resolution using CEPIA. Nat. Commun. 5, 4153 (2014).

15. Henderson, M. J. et al. A Low Affinity GCaMP3 Variant (GCaMPer) for Imaging the Endoplasmic Reticulum Calcium Store. PLoS One. 10, e0139273 (2015).

16. Inoue, M. et al. Rational design of a high-affinity, fast, red calcium indicator R-CaMP2. Nat. Methods. 12, 64-70 (2015).

17. Akerboom, J. et al. Genetically encoded calcium indicators for multi-color neural activity imaging and combination with optogenetics. Front Mol. Neurosci. 6, 2 (2013).

18. Berlin, S. et al. Photoactivatable genetically encoded calcium indicators for targeted neuronal imaging. Nat. Methods. 12, 852-858 (2015).

19. Chen, T. W. et al. Ultrasensitive fluorescent proteins for imaging neuronal activity. Nature. 499, 295-300 (2013).

20. Muto, A., Ohkura, M., Abe, G., Nakai, J. \& Kawakami, K. Real-time visualization of neuronal activity during perception. Curr. Biol. 23, 307-311 (2013).

21. Ohkura, M. et al. Genetically encoded green fluorescent $\mathrm{Ca}^{2+}$ indicators with improved detectability for neuronal Ca ${ }^{2+}$ signals. $P L o S$ One. 7, e51286 (2012).

22. Podor, B. et al. Comparison of genetically encoded calcium indicators for monitoring action potentials in mammalian brain by twophoton excitation fluorescence microscopy. Neurophotonics. 2, 021014 (2015).

23. Badura, A., Sun, X. R., Giovannucci, A., Lynch, L. A. \& Wang, S. S. Fast calcium sensor proteins for monitoring neural activity. Neurophotonics. 1, 025008 (2014).

24. Sun, X. R. et al. Fast GCaMPs for improved tracking of neuronal activity. Nat. Commun. 4, 2170 (2013).

25. Helassa, N. et al. Fast-Response Calmodulin-Based Fluorescent Indicators Reveal Rapid Intracellular Calcium Dynamics. Sci. Rep. 5, 15978 (2015).

26. Török, K. \& Trentham, D. R. Mechanism of 2-chloro-( $\varepsilon$-amino-Lys - $\left._{75}\right)$-[6-[4-(N,N-diethylamino)phenyl]-1,3,5-triazin-4-yl] calmodulin interactions with smooth muscle myosin light chain kinase and derived peptides. Biochemistry. 33, 12807-12820 (1994).

27. Ding, J., Luo, A. F., Hu, L., Wang, D. \& Shao, F. Structural basis of the ultrasensitive calcium indicator GCaMP6. Sci. China Life Sci. 57, 269-274 (2014).

28. Persechini, A., White, H. D. \& Gansz, K. J. Different mechanisms for $\mathrm{Ca}^{2+}$ dissociation from complexes of calmodulin with nitric oxide synthase or myosin light chain kinase. J. Biol. Chem. 271, 62-67 (1996).

29. Faas, G. C., Raghavachari, S., Lisman, J. E. \& Mody, I. Calmodulin as a direct detector of $\mathrm{Ca}^{2+}$ signals. Nat. Neurosci. 14, 301-304 (2011).

30. Dunlap, T. B., Kirk, J. M., Pena, E. A., Yoder, M. S. \& Creamer, T. P. Thermodynamics of binding by calmodulin correlates with target peptide alpha-helical propensity. Proteins. 81, 607-612 (2013).

31. Schilling, W. P., Sinkins, W. G. \& Estacion, M. Maitotoxin activates a nonselective cation channel and a P2Z/P2X(7)-like cytolytic pore in human skin fibroblasts. Am. J. Physiol. 277, C755-C765 (1999).

32. Gill, S. C. \& von Hippel, P. H. Calculation of protein extinction coefficients from amino acid sequence data. Anal. Biochem. 182, 319-326 (1989).

33. Tsien, R. Y. New calcium indicators and buffers with high selectivity against magnesium and protons: design, synthesis, and properties of prototype structures. Biochemistry. 19, 2396-2404 (1980).

34. Schoenmakers, T. J., Visser, G. J., Flik, G. \& Theuvenet, A. P. CHELATOR: an improved method for computing metal ion concentrations in physiological solutions. Biotechniques. 12, 870-879 (1992).

35. Emptage, N., Bliss, T. V. \& Fine, A. Single synaptic events evoke NMDA receptor-mediated release of calcium from internal stores in hippocampal dendritic spines. Neuron. 22, 115-124 (1999).

36. Stoppini, L., Buchs, P. A. \& Muller, D. A simple method for organotypic cultures of nervous tissue. J. Neurosci. Methods. 37, 173-182 (1991).

37. McAllister, A. K. Biolistic transfection of neurons. Sci. STKE. 2000, 11 (2000).

38. Schneider, C. A., Rasband, W. S. \& Eliceiri, K. W. NIH Image to ImageJ: 25 years of image analysis. Nat. Methods. 9, 671-675 (2012).

\section{Acknowledgements}

This work was funded by Wellcome Trust Project Grant 094385/Z/10/Z and BBSRC Project Grant BB/M02556X/1 to K.T., and by CIHR Grant MOP-123514 and NSERC Grant RGPIN-170421 to A.F. Dr. Silke Kerruth and Dr. Elizabeth R. Morris are thanked for comments on the manuscript. Use of the 3i-spinning confocal microscope at the Institute of Translational Medicine, Cellular and Molecular Physiology, University of Liverpool is acknowledged.

\section{Author Contributions}

N.H. generated mutant proteins, carried out biophysical characterisation and data analysis, cell imaging, generated figures; B.P. and A.F. designed, performed and analysed experiments in hippocampal slices; K.T. designed and supervised the project, wrote the paper and carried out kinetic modelling. 


\section{Additional Information}

Supplementary information accompanies this paper at http://www.nature.com/srep

Competing financial interests: The authors declare no competing financial interests.

How to cite this article: Helassa, N. et al. Design and mechanistic insight into ultrafast calcium indicators for monitoring intracellular calcium dynamics. Sci. Rep. 6, 38276; doi: 10.1038/srep38276 (2016).

Publisher's note: Springer Nature remains neutral with regard to jurisdictional claims in published maps and institutional affiliations.

(c) (i) This work is licensed under a Creative Commons Attribution 4.0 International License. The images or other third party material in this article are included in the article's Creative Commons license, unless indicated otherwise in the credit line; if the material is not included under the Creative Commons license, users will need to obtain permission from the license holder to reproduce the material. To view a copy of this license, visit http://creativecommons.org/licenses/by/4.0/

(C) The Author(s) 2016 


\section{SCIENTIFIC REP RTS}

OPEN Corrigendum: Design and mechanistic insight into ultrafast calcium indicators for monitoring intracellular calcium dynamics

Nordine Helassa, Borbala Podor, Alan Fine \& Katalin Török

Scientific Reports 6:38276; doi: 10.1038/srep38276; published online 06 December 2016; updated on 25 January 2017

This Article contains a typographical error. In the Results section,

'With measured molar extinction coefficients $\varepsilon_{\mathrm{o}(497 \mathrm{~nm})}$ of $50294 \pm 259 \mathrm{M}^{-1} \mathrm{~cm}^{-1}$ for $\mathrm{Ca}^{2+}$-saturated GCaMP6f and $1564 \pm 1140 \mathrm{M}^{-1} \mathrm{~cm}^{-1}$ for $\mathrm{Ca}^{2+}$-saturated GCaMP6f ${ }_{u}$, brightness values of 29673 and $7197 \mathrm{M}^{-1} \mathrm{~cm}^{-1}$ were obtained for GCaMP6f and GCaMP6f ${ }_{u}$, respectively.

should read:

'With measured molar extinction coefficients $\varepsilon_{0(497 \mathrm{~nm})}$ of $50294 \pm 259 \mathrm{M}^{-1} \mathrm{~cm}^{-1}$ for $\mathrm{Ca}^{2+}$-saturated GCaMP6f and $15646 \pm 1140 \mathrm{M}^{-1} \mathrm{~cm}^{-1}$ for $\mathrm{Ca}^{2+}$-saturated $\mathrm{GCaMP} 6 \mathrm{f}_{w}$, brightness values of 29673 and $7197 \mathrm{M}^{-1} \mathrm{~cm}^{-1}$ were obtained for GCaMP6f and GCaMP6f ${ }_{u}$, respectively'.

(c) (1) This work is licensed under a Creative Commons Attribution 4.0 International License. The images or other third party material in this article are included in the article's Creative Commons license, unless indicated otherwise in the credit line; if the material is not included under the Creative Commons license, users will need to obtain permission from the license holder to reproduce the material. To view a copy of this license, visit http://creativecommons.org/licenses/by/4.0/

() The Author(s) 2017 